\title{
UN SDGs Implementation Level in the Urban Sector in Korea: Focusing on a Framework Application Based on Relative Effi- ciency Theory
}

\author{
Jonghoon Yooㄹ, Minkyoung Choi ${ }^{2}$ and Byungseol Byun ${ }^{3, *}$ \\ 1 Land and Housing Institute, Daejeon 34047, Korea; yjh@lh.or.kr \\ 2 Department of Urban Regeneration, Inha University, 100 Inha-ro, Michuhol-gu, Incheon 22212, Korea; \\ cmk5626@naver.com \\ 3 Department of Public Administration, Inha University, 100 Inha-ro, Michuhol-gu, Incheon 22212, Korea; \\ * Correspondence: byun@inha.ac.kr; Tel.: +82-10-3258-4488
}

\begin{abstract}
The purpose of this study was to evaluate the implementation level of urban Sustainable Development Goals (SDGs) in the Republic of Korea and to measure the extent of internal and external impacts on the implementation level. An evaluation framework was established based on relative efficiency theory, and the implementation level of urban SDGs at the local government unit in the Republic of Korea was examined by performing an analysis of each stage. First, in reference to the 2018 cross-section, the implementation level of target 11.2 (public transportation) was assessed as excellent across the country, compared with the implementation level of targets 11.5 (disaster safety), 11.6 (environment), and 11.7 (public space), which were assessed as needing improvement. Second, the factors positively impacting the implementation level of target 11.2 were urban population, GRDP, financial independence, urbanization area, and bus-only lanes, whereas the factors positively impacting the implementation level of target 11.5 were population density and GRDP. The positive factors influencing the implementation level of target 11.6 (air quality sector) were found to be GRDP, financial independence, administrative area, and renewable energy generation, whereas the effective factors of the implementation level of target 11.6 (waste management sector) were analyzed as GRDP, financial independence, and the population density of households in the waste management area. The positive factors influencing the implementation level of target 11.7 were GRDP, financial independence, administrative area, and green area.
\end{abstract}

Keywords: UN SDGs; urban agenda; goal 11; relative efficiency; data envelopment analysis (DEA)

\section{Introduction}

The Sustainable Development Goals (SDGs) formally adopted at the United Nations (UN) summit in September 2015 describe a common global agenda and a new order in the international community that requires all countries to achieve their goals. The SDGs relate to almost all areas, including economic growth, environmental sustainability, global partnership and governance, along with the problems faced by developing countries, mainly in terms of social development, such as eradication of absolute poverty and disease, and protection of infants and mothers, which were achieved in the existing Millennium Development Goals (MDGs). Importantly, the SDGs also require the participation and responsibility of developed countries, and are not limited to developing countries. Since the Republic of Korea is a member of the international community and a member of the OECD $\mathrm{DAC}$, the implementation of and active participation in SDGs are necessary; as such, KSDGs, the national SDGs of the Republic of Korea, were established as a national plan in 2018 to present implementation details.

Among the 17 goals constituting the SDGs, the urban agenda is goal 11, which consists of housing, public transportation, urban planning and management, urban cultural 
heritage, disaster safety, and urban environment (air quality and waste management), along with detailed goals for their implementation. Therefore, despite prevailing over the diversification of participants compared to the MDGs in the past, it is necessary to preemptively respond and take a leading role in the public sector, including local governments, to lay the groundwork for achieving the goal [1]. In other words, the implementation and achievement of urban SDGs at the regional level are important issues, and the implementation of urban SDGs can be viewed as being directly connected to the provision of public services to society. The Sustainable Development Solution Network (SDSN), which contributed to the establishment of the SDGs, asserts that all cities be economically productive, socially inclusive, and environmentally sustainable [2]. In order to achieve the goals of the local government, it emphasizes the need to monitor and evaluate the level of implementation in terms of efficiency as well as the role of local governments, such as establishing implementation plans [3].

In accordance with the research background, this paper presents a framework for evaluating the urban SDGs' implementation level based on relative efficiency theory and evaluates the implementation level of the urban SDGs of the 17 regional governments in the Republic of Korea through this framework. In particular, the application of this framework aims to show which of the 17 local governments have relatively good levels of implementation, what causes inefficiencies, and what internal and external factors affect the implementation level of urban SDGs.

This remainder of this paper is organized as follows: Section 2 mainly discusses the theoretical background and methodologies, such as the SDGs and urban agendas as development goals for post-2015, relative efficiency theory and means of analysis, as well as providing a review of the related research. Section 3 presents the detailed and step-bystep research procedure of our empirical analysis, such as the design of the implementation level evaluation framework and the selection of analysis models accordingly. Section 4 illustrates empirical analysis results regarding the implementation level of urban SDGs by Korean local governments through a framework based on relative efficiency theory. Finally, Section 5 reports implications based on the empirical analysis, and proposes future research avenues.

\section{Theoretical Discussion and Methodology}

\subsection{SDGs and Urban SDGs as Post-2015 Development Goals}

The SDGs were discussed under the initiative of the UN, and were established by three pillars: the UN System Task Team, the UN High-Level Panel of Eminent Persons on the Post-2015 Development Agenda (HLP), and the UN Open Working Group. As shown in Figure 1, the three pillars can be seen in the order of the establishment process, and the role of each pillar had a profound impact on the establishment of the SDGs as the post2015 development goals.

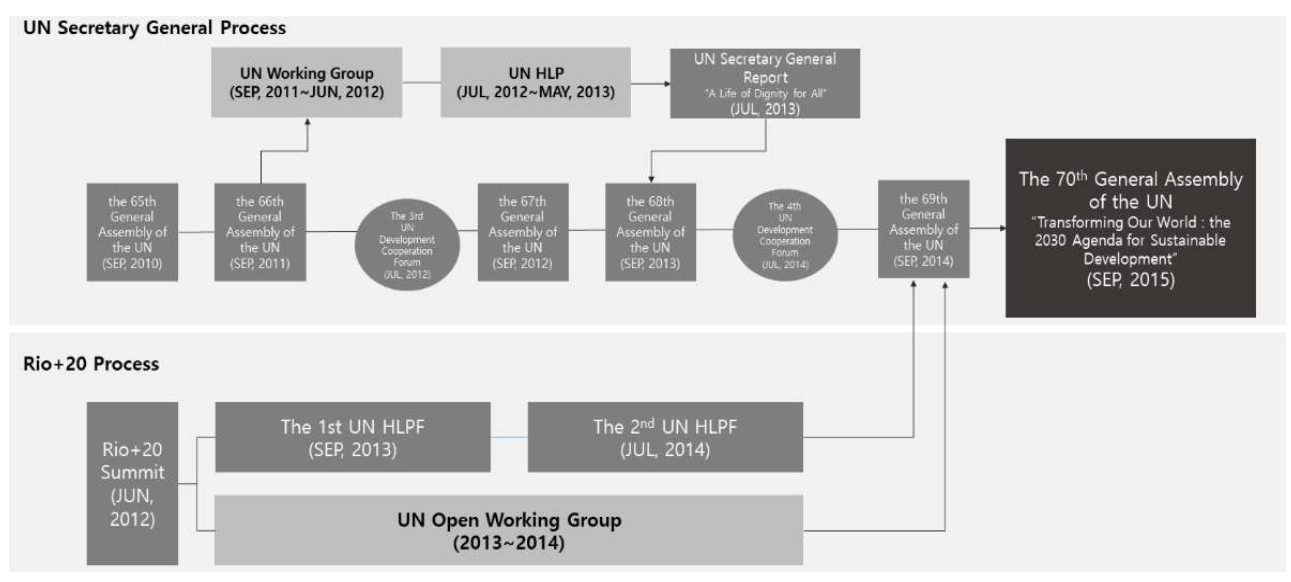

Figure 1. Sustainable Development Goals (SDGs) establishment process. 
The SDGs comprise 169 targets within 17 goals based on the premise of People, Planets, Prosperity, Peace, and Partnerships (5Ps), declared in the 2030 Transforming Our World: The 2030 Agenda for Sustainable Development. The achievement of a goal is evaluated by one or two indicators assigned to each target.

As post-2015 development goals, the SDGs are of significance in three aspects: including broader categories of goals compared to the past MDGs, introducing goals for developed countries, and, as a global task, involving diverse stakeholders, including civil society, businesses, and philanthropy foundations, not limited to the United Nations and governments.

Of the 17 goals that compose the SDGs, the urban SDGs (goal 11) are focused on making cities and human settlements incorporated, safe, resilient, and sustainable. The main contributors to the cities' SDGs setup are UN Habitat and SDSN. UN Habitat defined sustainable cities as environmentally sustainable, socially integrated, economically productive, and resilient cities [4] through the Sustained Cities and Human Settlements in the Post-2015 UN Development Agenda, a prototype of goal 11 proposed in the process of establishing goal 11. In addition, the SDSN emphasized that discussions on urban sustainability are needed to reach national sustainability. In particular, considering the need to initiate a total of nine urban goals and the promotion of economic activity through cohesion in cities, it is crucial to indicate that cities are central to social change and have local governments capable of responding quickly; hence, such spaces can be in harmony with sustainable development rather than considering it as problematic [2].

Table 1 provides a detailed description of goal 11. Of the total 10 targets, 11.1 to 11.7 are subject-specific objectives that outline improvements, and 11.a to 11.c are means of implementation (MoI).

Table 1. Targets of goal 11 [5].

\begin{tabular}{|c|c|}
\hline Target & Target description \\
\hline 11.1 & $\begin{array}{l}\text { By } 2030 \text {, ensure access for all to adequate, safe, and affordable housing } \\
\text { and basic services, and upgrade slums. }\end{array}$ \\
\hline 11.2 & $\begin{array}{l}\text { By } 2030 \text {, provide access to safe, affordable, accessible, and sustainable } \\
\text { transport systems for all, improving road safety, notably by expanding } \\
\text { public transport, with special attention to the needs of those in vulner- } \\
\text { able situations, women, children, persons with disabilities, and older } \\
\text { persons. }\end{array}$ \\
\hline 11.3 & $\begin{array}{l}\text { By } 2030 \text {, enhance inclusive and sustainable urbanization and capacity } \\
\text { for participatory, integrated, and sustainable human settlement plan- } \\
\text { ning and management in all countries. }\end{array}$ \\
\hline 11.4 & $\begin{array}{l}\text { Strengthen efforts to protect and safeguard the world's cultural and } \\
\text { natural heritage. }\end{array}$ \\
\hline 11.5 & $\begin{array}{l}\text { By } 2030 \text {, significantly reduce the number of deaths and the number of } \\
\text { people affected, and substantially decrease the direct economic losses } \\
\text { relative to global gross domestic product caused by disasters, includ- } \\
\text { ing water-related disasters, with a focus on protecting the poor and } \\
\text { people in vulnerable situations. }\end{array}$ \\
\hline 11.6 & $\begin{array}{l}\text { By } 2030, \text { reduce the adverse per capita environmental impact of cities, } \\
\text { including by paying special attention to air quality and municipal and } \\
\text { other waste management. }\end{array}$ \\
\hline
\end{tabular}


By 2030, provide universal access to safe, inclusive, accessible, green,

11.7 and public spaces, in particular for women and children, older persons, and persons with disabilities.

\begin{tabular}{ll}
\hline 11.a & $\begin{array}{l}\text { Support positive economic, social, and environmental links between } \\
\text { urban, peri-urban, and rural areas by strengthening national and re- } \\
\text { gional development planning. }\end{array}$ \\
& By 2020, substantially increase the number of cities and human settle- \\
& ments adopting and implementing integrated policies and plans to- \\
& wards inclusion, resource efficiency, mitigation and adaptation to cli- \\
11.b & mate change, resilience to disasters, and develop and implement, in \\
& line with the Sendai Framework for Disaster Risk Reduction 2015- \\
& 2030, holistic disaster risk management at all levels. \\
\hline & Support least developed countries, including through financial and \\
& technical assistance, in building sustainable and resilient buildings uti- \\
11.c & lizing local materials.
\end{tabular}

\subsection{Theoretical Concepts and Methodology of Efficiency}

\subsubsection{Conceptual Approach to Efficiency}

Efficiency is usually defined as the ratio of performance earned to the effort or resources put into it. In other words, high efficiency means that fewer resources are required to achieve higher results or achieve similar results with the same resources. The efficiency studies conducted to date have applied various definitions of efficiency, including the degree to which the input maximizes the level of output [6], the ratio of the output to the quantitative aspects of the service, including the human and physical resources used to produce the service product [7], and the best performance a particular organization can demonstrate by a certain level of production at a minimum cost [8]. Ultimately, by summarizing the conceptual approach of efficiency, it can be seen that efficiency is not only related to either aspect of input or output, but is a concept that focuses on input and output and the relationship between the two.

In order to assess the level of efficiency, the theoretical maximum output or minimum input levels must be identifiable. Moreover, the production probability set introduced to assess the maximum yield or minimum input levels is an important approach to the concept of efficiency [9]. This is because the premise of the most efficient state is required, rather than simply calculating the ratio of input to output. If a certain level of output can be produced with a certain level of input, in this case, a combination of input and output is considered to be possible, and the combination of possible input and output is defined as the production probability set [10]. However, as shown in Figure 2, the question of whether the dotted line is regarded as an efficiency frontier or a solid line is a matter of how the efficiency frontier is determined. It refers to a shipping concatenation or set consisting of an efficient decision-making unit (DMU) among the DMUs subject to evaluation. Changes in how these efficiency boundaries are determined may also result in different outcomes, requiring several assumptions, such as free disposability, convexity, and the return to scale (RTS). 


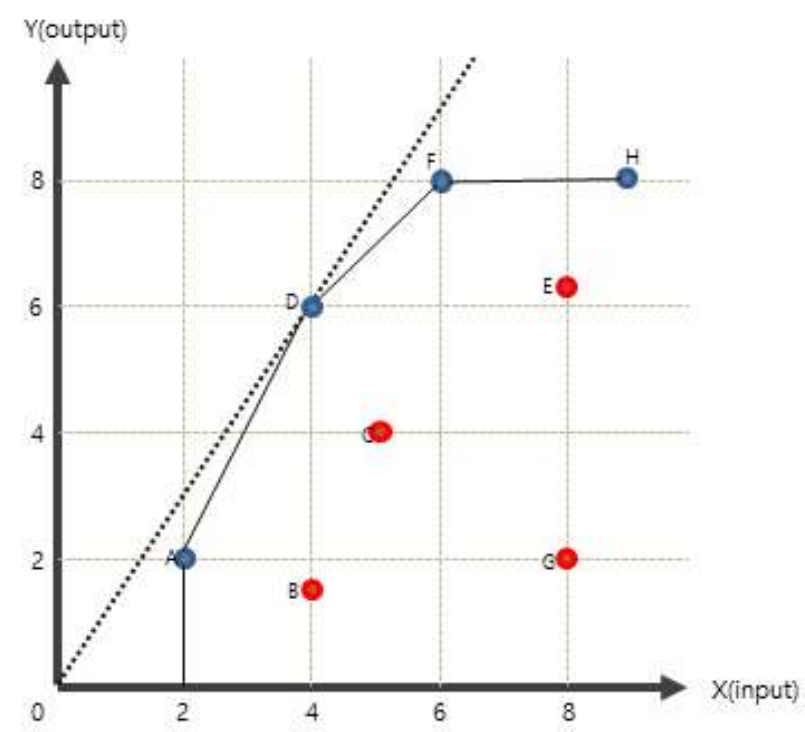

Figure 2. Composition of the efficiency frontier and the production probability set of one output unit per input unit.

As described above, efficiency can be calculated as the ratio of the amount of output factor to the amount of input factor, but the absolute efficiency of this concept has several limitations. It is difficult to compare the size of the efficiency score, since the results change whenever the analysis units, which are input and output variables, are different. As such, if the efficiency score does not have a certain range of values and changes according to the analysis unit, it is difficult to compare efficiency between DMUs in a situation where there are multiple inputs and outputs [10]. Therefore, in order to derive an efficiency boundary according to the relationship between a number of input and output variables, it is necessary to introduce a concept of relative efficiency that compares the DMU with the highest efficiency in the efficiency boundary with the corresponding DMU. The analysis in this paper is based on the concept of relative efficiency.

\subsubsection{The Need to Evaluate the Implementation Level in Terms of Efficiency}

Urban SDGs are vertical goals that are all related to countries, regions, and places. The MDGs were criticized for focusing only on national goals but failing to address subregional and local areas; thus, UN Habitat and SDSN, each involved in setting goal 11, considered a more regional approach by presenting the need to include a prototype and urban goal in goal 11.

In particular, SDSN presented strategies for localizing the SDGs after their adoption [3]. This localization strategy includes step-by-step implementation plans, such as the prioritization phase of sustainable development (Step 1), the establishment of regional SDGs in accordance with the global SDGs (Step 2), the establishment of local SDGs implementation plans (Step 3), and the monitoring of local SDGs and the efficiency level of program implementation (Step 4). This suggests the importance of monitoring at the urban level of action planning and action plans for sustainable development, verifying the efficiency of implementation levels and acknowledging the importance of the role of local governments in this series of processes [1]. The issues of housing, public transportation, urban planning, urban cultural heritage, disaster safety, and urban environment, which constitute the urban SDGs, are the issues to be addressed for providing public services to citizens, and the public sector belonging to the core industries of the public sector provides a shared understanding that the assessment of the implementation level is necessary from an efficiency perspective. 


\subsubsection{Methods for Efficiency Analysis}

Most scholars agree that efficiency is important for business or government activities [10]. However, the main reason why efficiency analysis is difficult is that activities in the real world are not composed of a simple relationship, such as one input to one output. Since most activities consist of multiple inputs and multiple outputs, it is essential to apply weights for each factor, but it is difficult to determine these weights, and the need to reflect multiple constraints limits the efficacy of efficiency analysis. Nevertheless, it is important to identify and address the causes of inefficiency and attempt to analyze efficiency to continuously improve competitiveness. Recently, various information systems have been established and used, and efficiency analysis is becoming easier than in the past due to the developments in statistical methodology.

A representative model for efficiency analysis is the data envelopment analysis (DEA) model. The DEA model has the advantage of enabling an efficiency analysis considering a number of input and output variables, and providing detailed information on whether the analyzed DMU operates efficiently compared to other DMUs, and the extent of inefficiency if it is inefficient. It also clarifies the scope and definition of the efficiency analysis. In efficiency analysis, the selection of input and output variables is an important issue, and if the DEA model is used, the unit of input and output variables can be free. For example, if evaluating the government's policy efficiency as a research problem, the budget amount can be used as an input variable, and input variables with different unit structures, such as the number of public servants and educational background, can be used. Conversely, monetary units can be used for output variables, and qualitative factors such as citizen satisfaction can also be used.

One of the criticisms raised despite the advantages of the DEA model is that it takes a non-parameter approach that does not assume the parameters of the population. In other words, it is difficult to check the random error of the score obtained by efficiency analysis. In this problem, a method of estimating the confidence interval of the efficiency score through a model such as the bootstrapping DEA model was proposed, thereby increasing the reliability of the analysis result. In addition, the DEA-window model application can track time-series efficiency changes.

\subsection{Review of Previous Studies and Resarch Differentiation}

Although the SDGs are relatively recent issues, research has been conducted in various fields. Among them, the major studies directly related to urban SDGs include those by Seong et al. [11], Lim et al. [12], Jeong [13], Han [14], Simon et al. [15], Satterthwaite [16], Sietchping et al. [17], and Valencia et al. [18].

Seong et al. [11] presented the background of SDGs 9 and 11 that have been pursued so far, trends in the international community, a review of the proposed indicators, a review of the major cases for SDGs application, and countermeasures. In particular, based on the official opinion survey presented by the UN Statistical Commission, a survey was conducted by domestic experts on the feasibility of measuring indicators, the suitability of indicators for each country, and the appropriateness of compliance with detailed goals and indicators. In accordance with the survey results, the practical significance of applying the urban SDGs agenda was demonstrated by analyzing actual cases of new towns in the Republic of Korea.

Lim et al. [12] conducted a study to determine the kind of international leadership in the development of new cities in the Republic of Korea against the indicators of SDG 11. The analysis was carried out for targets 11.1-11.7 of goal 11, and the analysis framework was presented centering on the cases that have been continuously applied by searching the initial new town cases, such as the first new town in the Seoul metropolitan area. According to this analysis framework, the characteristics of the development of new Korean towns were illustrated, and the international leadership of new towns in the Republic of Korea by each indicator was discussed. Ultimately, the results suggested that Korea's goal 
11 needs to focus on responding to the issues of low fertility, ageing, and population diversity.

Jeong [13] suggested the process of establishing urban SDGs at the regional level, focusing on the case of a municipality (Suwon City). Unlike previous studies, the research results were presented centering on the behavior of participants obtained through direct social experiments, and the institutional basis such as the establishment of the Ordinance for Sustainable Development, a dedicated department, related commissions, implementation plans, etc. This study emphasized the necessity of provision.

Han [14] developed assessment items and indicators for sustainable urban development and management to conduct evaluations on 72 cities with a population of more than 100,000 , and to distinguish, improve, and provide recommendations for sustainable cities.

Simon et al. [15] performed a case study that applies the indicators of goal 11 to cities in developed and developing countries. Goal 11 indicators were applied to five cities with regional representation, including Yetebori (Sweden), Manchester (U.K.), Bangalore (India), Cape Town (South Africa), and Kisumu (Kenya). As a result of the analysis, it was argued that efforts to develop appropriate indicators and improve usability were urgently needed to achieve goal 11 and to measure continuous levels of implementation.

Satterthwaite [16] presented the characteristics and implementation tasks of recent global agendas, including SDG 11, the Paris Climate Change Convention, and the New Urban Agenda (NUA).

Sietchping et al. [17] emphasized the role of national and local governments for the successful implementation of goal 11 and advocated for the establishment of a policy framework in line with goal 11.

Valencia et al. [18] emphasized the importance of the urban agenda centered on goal 11 and the NUA in establishing sustainable development, and argued that sustainable development can be achieved through urbanization. In particular, SDG 11 and the NUA were discussed at the national level, and the process of localization and adaptation of the global agenda were considered necessary for practical implementation.

Most previous studies are significant since they provide criticism of the current core issues and direction for the implementation of the SDG 11 in the future in several large frameworks of the engaged city: social development and economic growth, sustainability of the environment, and the establishment of governance. However, with the exception of a few, many previous studies were conducted at a discourse level rather than demonstrating objective results in accordance with empirical analysis procedures. Furthermore, even though achievement at the regional level is important, there is a lack of an appropriate logical relationship to the implementation level at the local scale.

In this study, we aimed to evaluate the objective level of performance by applying the theory of efficiency, which is the calculation against input, and the analysis method based on it, considering that the basis of achieving urban SDGs is the public service of the public sector. In addition, based on the results of quantitative analysis, the purpose of this study was to present the internal and exogenous factors influencing the analysis targets that affect the implementation level.

\section{Design of Framework for Evaluation of Implementation Level and Research Setting}

\subsection{Design of Framework for Evaluation of Implementation Level}

In this paper, analysis was performed according to the framework shown in Figure 3 to evaluate the implementation level of the urban SDGs for 17 local governments in Korea. 


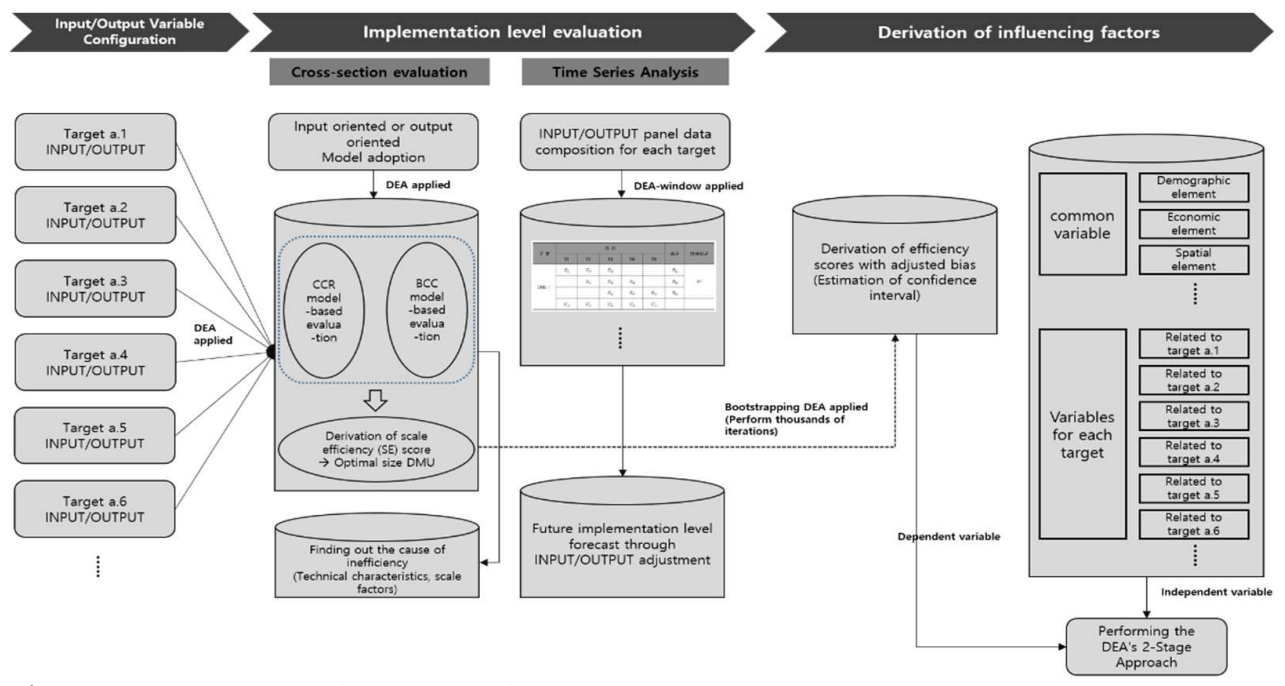

Figure 3. The evaluation framework of the urban SDGs' implementation level.

First, as an essential evaluation process, input and output variables for each target were selected. As the scope of the analysis, the focus was the target that constitutes goal 11, but we excluded those that do not fit the Korean conditions or for which it is difficult to obtain consistent analysis indicators across the 17 local governments. The targets excluded in this study due to the scope of the analysis were 11.1, 11.3, and 11.4. In order to use the DEA model, the most important process is the consistent composition of variables for analysis. Therefore, we performed an analysis based on the cross-section of 2018, which is the latest year in which consistent variables could be constructed for the 17 local governments.

The time-series data composition for tracking the multi-year performance level was analyzed by setting the five-year range from 2014 to 2018. Considering the first time when statistics related to Sejong's research (2014) were published (2012), the time range was set so that the SDGs were adopted in 2015 so that the transition of the implementation level before and after the adoption could be traced. The purpose of this study and the theoretical context of the DEA model were understood to adopt the input- or output-oriented model, and environmental variables were selected and established to derive the influencing factors through a two-stage approach. A case study was conducted for the snow surface variable of the efficiency score, where the analysis results using the DEA model were widely used in statistical analysis [10]. By using the efficiency score obtained through the DEA model as a dependent variable, potential variables that are assumed to affect the efficiency are placed as independent variables to analyze the relationship between them [9]. It is defined as a two-stage approach [19], where environmental variables are used as independent variables. This was also set up in this study based on 2018, the latest year for consistent data collection by the 17 local governments, in the same context as input and output variables.

Second, through the model, the implementation level of 17 local governments was evaluated, and the dependent variables necessary for the analysis of the influencing factors through a two-stage approach were derived. As a first step, the CCR and BCC efficiency scores for each target were derived using the standard DEA model, and the scale efficiency (SE) score was calculated; then, the implementation level of the 17 local governments in reference to the cross-section in 2018 was determined according to relative efficiency theory. Finally, we determined whether the cause of the inefficiency is a scale factor or a technology factor. The next step was a time-series analysis using the DEA window, which is not a critical step in deriving the dependent variable, but uses the established five-year input and output variables to examine the transition level of the implementation for each target. Lastly, in order to overcome the limitations of the DEA model, where statistical inference is difficult, by applying the bootstrapping DEA model and estimating 
the confidence interval for the efficiency score of each target, the efficiency score with adjusted bias was derived. The efficiency score with adjusted bias was used as the dependent variable.

Third, we used a two-stage approach to investigate the influence factors for each detailed target based on the cross-section in 2018, using the efficiency score with adjusted bias as the dependent variable and the environmental variable representing the internal and external environments of 17 local governments as an independent variable. The statistical methodology for the two-stage approach uses a Tobit regression equation and a quantile regression equation.

The urban SDGs adopt the input-oriented model, so they are public services provided by the government to citizens. The production of public services provided by the government allows arbitrary adjustment of inputs such as budget and manpower, while output is difficult to control. In addition, since the implementation level of urban SDGs by local governments becomes the output of public services, it has limitations in terms of meeting the basic needs of citizens [20].

\subsection{Selection of Input and Ouput Variables}

In the DEA model, since weights for input and output variables are determined within the model, the relative efficiency of a DMU is determined by the actual analysis values of the input and output variables included in the model. That is, the selection of input and output variables provides the fundamental basis for evaluating the implementation level of the urban SDGs using the DEA model. For the selection of such input and output variables, it is ideal to construct all variables related to the subject, but in reality, data acquisition is limited, so only some can be selected as variables in many cases [7].

There are no general rules for selecting input and output variables [10] but, in general, the variables used in verified studies were cited or selected by researchers through separate criteria. In this study, the latter method was followed because, as shown in a previous study, few studies have analyzed the development agenda using the DEA model, and research cases are lacking in which the implementation level has been quantitatively evaluated for the theme of the SDGs, making it difficult to select reliable inputs and outputs. Moreover, because of the nature of the analysis method, there is a limit on constructing data according to the data format of the institution providing the indicator, so the method selected by the researchers considering the characteristics of each detailed target will be more appropriate. In this study, input and output variables were constructed, as shown in Tables 2 and 3 respectively, considering the orientation point and data acquisition possibility of each target.

Table 2. Description of input variables.

\begin{tabular}{|c|c|c|c|}
\hline \multicolumn{3}{|c|}{ Division } & \multirow[t]{2}{*}{ Variable description (by local government) } \\
\hline Variab & ame & Unit & \\
\hline \multirow{4}{*}{ Target 11.2} & INPUT1 & KRW (mil.) & $\begin{array}{l}\text { Transportation and transportation sector (public transportation) } \\
\text { budget among general accounting expenditures }\end{array}$ \\
\hline & INPUT2 & Person & Number of public officials in charge of public transportation \\
\hline & INPUT3 & Places & Number of bus stops per 1000 people \\
\hline & INPUT4 & person & Capacity per bus \\
\hline \multirow{2}{*}{ Target 11.5} & INPUT5 & KRW (mil.) & Disaster management fund \\
\hline & INPUT6 & person & Number of public officials in charge of disaster safety \\
\hline $\begin{array}{l}\text { Target } 11.6 \\
\text { (air quality) }\end{array}$ & INPUT7 & KRW (mil.) & $\begin{array}{l}\text { Out of general account expenditure, environmental protection } \\
\text { sector (air quality sector) budget }\end{array}$ \\
\hline
\end{tabular}




\begin{tabular}{|c|c|c|c|}
\hline & INPUT8 & person & Number of public officials in charge of environment \\
\hline \multirow{3}{*}{$\begin{array}{c}\text { Target } 11.6 \\
\text { (waste } \\
\text { management) }\end{array}$} & INPUT9 & person & Waste management personnel \\
\hline & INPUT10 & KRW (thousand) & Waste management budget \\
\hline & INPUT11 & units & $\begin{array}{l}\text { Waste collection equipment } \\
\text { (collection vehicles and heavy equipment) }\end{array}$ \\
\hline \multirow[b]{2}{*}{ Target 11.7} & INPUT12 & person & Number of public officials in charge of parks and green areas \\
\hline & INPUT13 & KRW (mil.) & $\begin{array}{l}\text { Public spaces (parks and green areas) } \\
\text { among general accounting expenditures }\end{array}$ \\
\hline
\end{tabular}

Table 3. Description of output variables.

\begin{tabular}{|c|c|c|c|}
\hline \multicolumn{3}{|c|}{ Division } & \multirow[t]{2}{*}{ Variable description (by local government) } \\
\hline Variable & name & Unit & \\
\hline \multirow{3}{*}{ Target 11.2} & OUTPUT1 & score & Satisfaction with public transportation-oriented operation \\
\hline & OUTPUT2 & score & Satisfaction regarding transportation \\
\hline & OUTPUT3 & score & $\begin{array}{l}\text { Satisfaction with the distance and time access of public transpor- } \\
\text { tation }\end{array}$ \\
\hline \multirow{3}{*}{ Target 11.5} & OUTPUT4 & case & $\begin{array}{l}\text { Occurrence of social disasters (collapse, safety accident, explo- } \\
\text { sion, environmental pollution, traffic accident, forest fire, and } \\
\text { fire) }\end{array}$ \\
\hline & OUTPUT5 & case & Number of emergency rescue activities \\
\hline & OUTPUT6 & KRW (thousand) & Amount of damage due to natural disaster \\
\hline \multirow{5}{*}{$\begin{array}{l}\text { Target } 11.6 \\
\text { (air quality) }\end{array}$} & OUTPUT7 & $\mu \mathrm{g} / \mathrm{m}^{3}$ & $\begin{array}{l}\text { Fine dust (PM10) pollution level (annual average of monthly } \\
\text { measurement results) }\end{array}$ \\
\hline & OUTPUT8 & ppm & $\begin{array}{l}\text { Sulfurous acid gas air pollution level (annual average of monthly } \\
\text { measurement results) }\end{array}$ \\
\hline & OUTPUT9 & ppm & $\begin{array}{l}\text { Air pollution degree of nitrogen dioxide (annual average of } \\
\text { monthly measurement results) }\end{array}$ \\
\hline & OUTPUT10 & ppm & $\begin{array}{l}\text { Carbon monoxide air pollution level (annual average of } \\
\text { monthly measurement results) }\end{array}$ \\
\hline & OUTPUT11 & ppm & $\begin{array}{l}\text { Ozone air pollution level (annual average of monthly measure- } \\
\text { ment results) }\end{array}$ \\
\hline \multirow{2}{*}{$\begin{array}{l}\text { Target } 11.6 \\
\quad \text { (waste } \\
\text { management) }\end{array}$} & OUTPUT12 & ton/day & Waste treatment amount (landfill and incineration) \\
\hline & OUTPUT13 & $\%$ & Waste recycling rate (general waste and business waste) \\
\hline \multirow{2}{*}{$\begin{array}{c}\text { Target } \\
11.7\end{array}$} & OUTPUT14 & $\mathrm{m}^{2}$ & Park area \\
\hline & OUTPUT15 & $\mathrm{m}^{2}$ & Open space area \\
\hline
\end{tabular}


Environmental variables were the independent variables used in the two-stage approach to examine the factors influencing the implementation level of the urban SDGs by Korean local governments, and consisted of indicators related to endogenous factors or the external environment. The environmental variables were divided into common variables that consider the regional characteristics of each local government and variables for each specific target that consider the direction and characteristics of each target.

The common variables included variables that reflect the demographic, economic, and spatial characteristics of each local government, and are shown in Table 4.

Table 4. Description of environment variables (common variables).

\begin{tabular}{ccl}
\hline Variable type & Variable name & \multicolumn{1}{c}{ Variable description (by local government) } \\
\hline Pemographic & POP_DENSITY & Population (person) \\
& POP_URBAN & Urban population (person) \\
\hline Economic & GRDP & GRDP (KRW billion) \\
& FIR & Financial independence $(\%)$ \\
\hline \multirow{2}{*}{ Spatial } & SQUARE & Administrative area $\left(\mathrm{m}^{2}\right)$ \\
& SQUARE_URBAN & Urbanization area $\left(\mathrm{m}^{2}\right)$ \\
\hline
\end{tabular}

Variables for each target were the endogenous factors and external environment for public transport (target 11.2), disaster safety (target 11.5), environment (target 11.6), and public space (target 11.7), which are the characteristic themes of each target.

The indicators that could be measured were selected, which are summarized in Table 5 .

Table 5. Description of environmental variables (variables for each target).

\begin{tabular}{|c|c|c|}
\hline Target & Variable name & Variable description (by local government) \\
\hline \multirow{3}{*}{11.2} & REG_AUTOMOBILE & Number of automobile registrations (units) \\
\hline & ROAD_LENGTH & Road extension (km) \\
\hline & BUSROAD_LENGTH & Extended bus lanes $(\mathrm{km})$ \\
\hline \multirow{2}{*}{11.5} & ESTABLISHMENT & Number of businesses (pieces) \\
\hline & REG_AUTOMOBILE & Number of automobile registrations (units) \\
\hline \multirow{4}{*}{$\begin{array}{c}11.6 \\
\text { (air quality) }\end{array}$} & REG_AUTOMOBILE & Number of automobile registrations (units) \\
\hline & SQUARE_GREEN_BUFFER & Buffer green area $\left(\mathrm{m}^{2}\right)$ \\
\hline & MANUFACTURING & Number of manufacturers (pieces) \\
\hline & RENEWABLE_ENERGY & Renewable energy generation (toe) \\
\hline Target 11.6 & SQUARE_WM & Waste management area $\left(\mathrm{km}^{2}\right)$ \\
\hline management) & SQUARE_DENSITY_WM & Population density in waste management area (person $\left./ \mathrm{km}^{2}\right)$ \\
\hline Target 11.7 & SQUARE_GREEN & Green area $\left(\mathrm{m}^{2}\right)$ \\
\hline
\end{tabular}

4. Empirical Analysis

4.1. Summary of Data Analysis 
Similar to other studies, studies using DEA models also require an understanding of the basic characteristics of the data analysis before performing the analysis. To this end, it is necessary to conduct a comprehensive technical statistical analysis that identifies the average, standard deviation, maximum, and minimum of the data. In this section, prior to discussing the empirical analysis, a descriptive statistical analysis of the selected input and output variables and environmental variables is presented, and purification means of data analysis are discussed.

Tables 6-8 provide the results of descriptive statistics analysis of environmental variables, which are independent variables of the cross-sectional standard, input and output variables, and the second-stage approach in 2018.

Table 6. Results of the technical statistical analysis of the input variables.

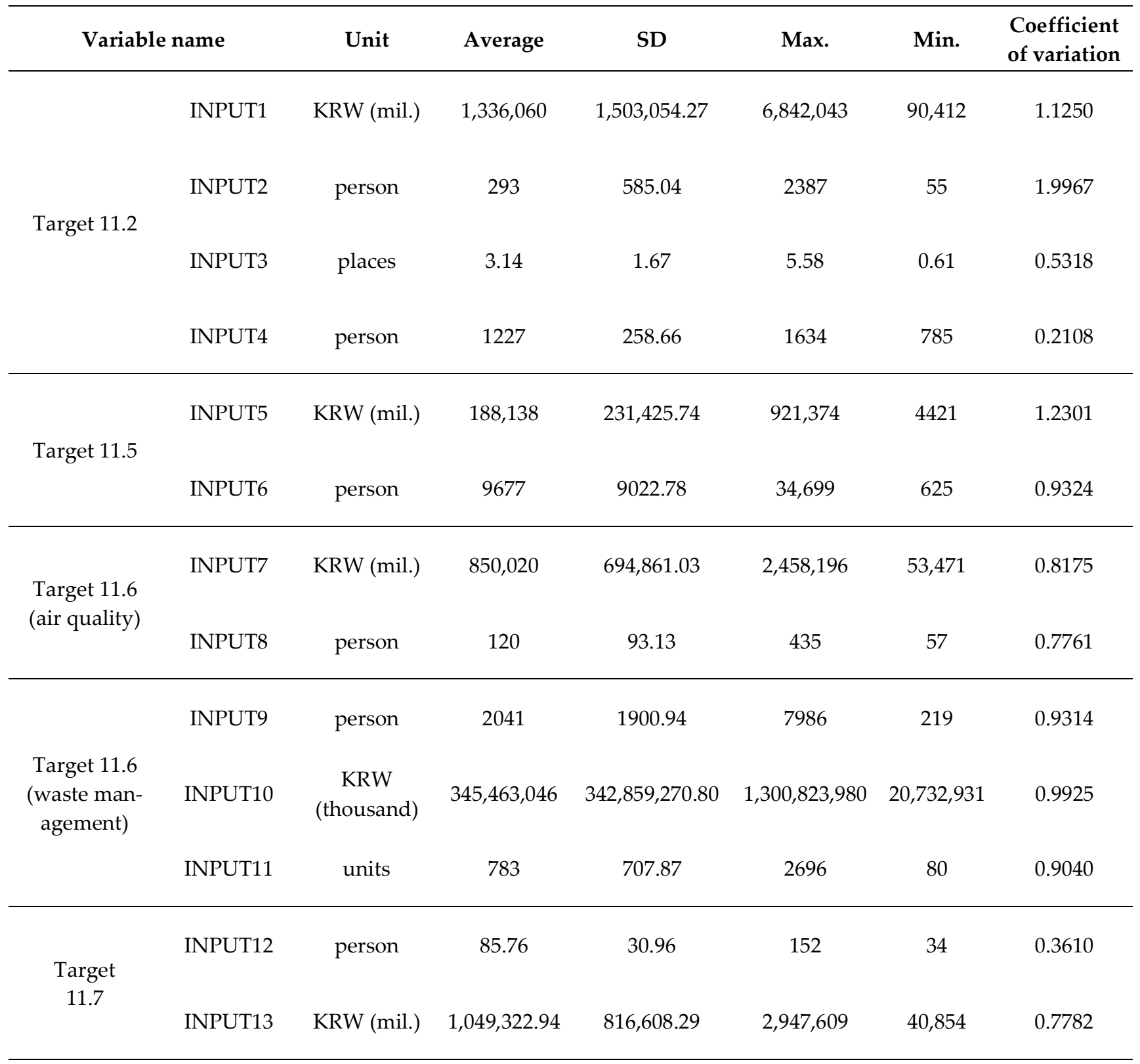

Note: $\mathrm{N}=17$.

Table 7. Results of the technical statistical analysis of the output variables. 


\begin{tabular}{|c|c|c|c|c|c|c|c|}
\hline \multicolumn{2}{|c|}{ Variable name } & \multirow{2}{*}{$\begin{array}{c}\text { Unit } \\
\text { score }\end{array}$} & \multirow{2}{*}{$\begin{array}{c}\text { Average } \\
4.50\end{array}$} & \multirow{2}{*}{$\begin{array}{c}\begin{array}{c}\text { Standard } \\
\text { deviation }\end{array} \\
0.20\end{array}$} & \multirow{2}{*}{$\begin{array}{c}\text { Max. } \\
4.93\end{array}$} & \multirow{2}{*}{$\begin{array}{l}\text { Min. } \\
4.12\end{array}$} & \multirow{2}{*}{$\begin{array}{c}\begin{array}{c}\text { Coefficient } \\
\text { of variation }\end{array} \\
0.0444\end{array}$} \\
\hline & OUTPUT1 & & & & & & \\
\hline \multirow[t]{3}{*}{ Target 11.2} & OUTPUT2 & score & 4.50 & 0.16 & 5.00 & 4.29 & 0.0356 \\
\hline & OUTPUT3 & score & 4.87 & 0.18 & 5.46 & 4.67 & 0.0370 \\
\hline & $11,017,781$ & case & 2598 & 2314.47 & 9,797 & 316 & 0.8909 \\
\hline \multirow{4}{*}{$\begin{array}{c}\text { KRW } \\
\text { (thousand) }\end{array}$} & OUTPUT5 & case & 47,323 & $51,588.38$ & 191,521 & 6189 & 1.0901 \\
\hline & OUTPUT6 & & & $24,310,723.57$ & $86,649,762$ & 0 & 1.2065 \\
\hline & OUTPUT7 & $\mu \mathrm{g} / \mathrm{m}^{3}$ & 43 & 6.49 & 53 & 26 & 0.1509 \\
\hline & OUTPUT8 & ppm & 0.004 & 0.001 & 0.006 & 0.003 & 0.2500 \\
\hline \multirow{3}{*}{$\begin{array}{l}\text { Target } 11.6 \\
\text { (air quality) }\end{array}$} & OUTPUT9 & ppm & 0.020 & 0.005 & 0.032 & 0.013 & 0.2500 \\
\hline & OUTPUT10 & ppm & 0.500 & 0.087 & 0.600 & 0.300 & 0.1740 \\
\hline & OUTPUT11 & ppm & 0.029 & 0.005 & 0.044 & 0.023 & 0.1724 \\
\hline \multirow{2}{*}{$\begin{array}{l}\text { Target } 11.6 \\
\text { (waste } \\
\text { management) }\end{array}$} & OUTPUT12 & ton/day & 1073 & 1017.6 & 4136 & 75 & 0.9484 \\
\hline & OUTPUT13 & $\%$ & 61 & 10.9 & 86 & 48 & 0.1787 \\
\hline \multirow{2}{*}{ Target 11.7} & OUTPUT14 & $\mathrm{m}^{2}$ & $54,344,399.65$ & $43,778,527.61$ & $177,254,954$ & $9,970,406$ & 0.8056 \\
\hline & OUTPUT15 & $\mathrm{m}^{2}$ & 793212.71 & $1,083,186.12$ & $4,864,779$ & 204,789 & 1.3656 \\
\hline
\end{tabular}

Note: $\mathrm{N}=17$.

Table 8. Results of the technical statistical analysis of the environmental variables.

\begin{tabular}{|c|c|c|c|c|c|c|c|}
\hline & $\begin{array}{l}\text { Element/ } \\
\text { target }\end{array}$ & Variable name & Unit & Average & $\begin{array}{l}\text { Standard } \\
\text { deviation }\end{array}$ & Max. & Min. \\
\hline \multirow{7}{*}{$\begin{array}{l}\text { Common } \\
\text { variables }\end{array}$} & \multirow{3}{*}{$\begin{array}{l}\text { Demo- } \\
\text { graphic } \\
\text { element }\end{array}$} & POP & person & $3,045,797$ & $3,292,667$ & $12,873,895$ & 280,100 \\
\hline & & POP_DENSITY & person $/ \mathrm{km}^{2}$ & 2171 & 3917 & 16,414 & 92 \\
\hline & & POP_URBAN & person & $2,773,383$ & $3,244,532$ & $12,312,095$ & 266,122 \\
\hline & \multirow{2}{*}{$\begin{array}{c}\text { Economic } \\
\text { element }\end{array}$} & GRDP & KRW(bil.) & 96,740 & 105,285 & 372,344 & 9019 \\
\hline & & FIR & $\%$ & 49.8 & 17.9 & 84.6 & 23.7 \\
\hline & \multirow{2}{*}{$\begin{array}{l}\text { Spatial } \\
\text { element }\end{array}$} & SQUARE & $\mathrm{m}^{2}$ & $5,902,322,717$ & $6,202,153,903$ & $19,031,416,972$ & $464,868,526$ \\
\hline & & $\begin{array}{c}\text { SQUARE_ } \\
\text { URBAN }\end{array}$ & $\mathrm{m}^{2}$ & $243,799,605$ & $169,658,546$ & $753,021,593$ & $40,799,579$ \\
\hline \multirow{4}{*}{$\begin{array}{c}\text { Variables } \\
\text { for each } \\
\text { target }\end{array}$} & \multirow{3}{*}{ Target 11.2} & $\begin{array}{c}\text { REG_- }_{-} \\
\text {AUTOMOBILE }\end{array}$ & units & $1,282,550.1$ & $1,193,916.8$ & $5,160,921$ & 110,360 \\
\hline & & ROAD_LENGTH & $\mathrm{km}$ & 6475.9 & 4424.1 & 13,604 & 402 \\
\hline & & $\begin{array}{c}\text { BUSROAD_ } \\
\text { LENGTH }\end{array}$ & $\mathrm{km}$ & 41.1 & 57.4 & 203.9 & 0 \\
\hline & Target 11.5 & $\begin{array}{l}\text { ESTABLISH- } \\
\text { MENT }\end{array}$ & pcs & 227,892 & $234,709.3$ & 827,983 & 10,480 \\
\hline
\end{tabular}




\begin{tabular}{|c|c|c|c|c|c|c|}
\hline & $\begin{array}{c}\text { REG }_{-} \\
\text {AUTOMOBILE }\end{array}$ & units & $1,282,550.1$ & $1,193,916.8$ & $5,160,921$ & 110,360 \\
\hline \multirow{4}{*}{$\begin{array}{l}\text { Target } 11.6 \\
\text { (air quality) }\end{array}$} & $\begin{array}{c}\text { REG }_{-} \\
\text {AUTOMOBILE }\end{array}$ & units & $1,282,550.1$ & $1,193,916.8$ & $5,160,921$ & 110,360 \\
\hline & $\begin{array}{c}\text { SQUARE_ } \\
\text { GREEN_BUFFER }\end{array}$ & $\mathrm{m}^{2}$ & $8,026,359$ & $6,520,934$ & $27,212,646$ & 410,425 \\
\hline & $\begin{array}{l}\text { MANUFAC } \\
\text {-TURING }\end{array}$ & pcs & $25,510.8$ & $30,925.8$ & 130,282 & 1093 \\
\hline & $\begin{array}{l}\text { RENEWABLE_ } \\
\text { ENERGY }\end{array}$ & toe & $967,552.1$ & $934,765.2$ & $3,229,557$ & 65,440 \\
\hline $\begin{array}{l}\text { Target } 11.6 \\
\text { (waste }\end{array}$ & SQUARE_WM & $\mathrm{km}^{2}$ & 5813.0 & 6067.7 & $18,961.6$ & 464.9 \\
\hline $\begin{array}{l}\text { manage- } \\
\text { ment) }\end{array}$ & $\begin{array}{c}\text { SQUARE_ } \\
\text { DENSITY_WM }\end{array}$ & person $/ \mathrm{km}^{2}$ & 2186.3 & 3887.3 & $16,287.9$ & 98.3 \\
\hline $\begin{array}{c}\text { Target } \\
11.7\end{array}$ & SQUARE_GREEN & $\mathrm{m}^{2}$ & $13,912,661.9$ & $17,874,037.9$ & $79,089,449$ & 582,075 \\
\hline
\end{tabular}

Note: $\mathrm{N}=17$.

The results of the technical statistical analysis show that there is a large difference between the local governments, which is due to the differences in the internal and external size of each local government. Local governments with relatively large population size (urban population) and administrative area (urbanization area) have a larger scale of investment in terms of human resources, finance, and infrastructure than local governments. Therefore, not only does the use of absolute levels of raw materials violate the purpose of this study, the aim of which was to analyze relative efficiency, but it also raises a question about the reliability of the results. Some prior studies used ratio variables through artificial transformations, such as per capita variables, to mitigate these limitations. However, the use of artificial rate variables in selecting inputs and outputs can cause other problems. This is because using these variables does not satisfy the convexity of the DEA model. In response, leading researchers argued that it may not be desirable to use the ratio variable together with the variables corresponding to the denominator of the proportion variable as input and output variables of the DEA model, except in special cases $[21,22,10]$. Therefore, a separate process of conversion into relative analysis data is required.

When using the DEA model, the size of the unit varies widely depending on the characteristics of each variable. For example, if the value of input variable 1 is 1,000,000 and the value of input variable 2 is 0.1 , the difference between the values of each variable is large. Therefore, when calculating the optimal solution, the accuracy of the analysis may degrade due to the problem of decimal places [10]. This is a problem of adjusting the difference in the size of the variable, and even if the difference in the size of the unit of the variable is large, a separate data purification means is required.

In this study, to overcome the problem of the use of absolute analysis data and the size difference between variables, mean normalization, which is used for efficiency analysis, was applied after dividing the value of the variable by each mean. The mean normalization is calculated by the following equation:

$$
x_{\text {normal }}=\frac{x_{i}}{\bar{x}}\left(\text { however }, \bar{x}=\frac{1}{n} \sum_{i=1}^{n} x_{i}\right)
$$

Applying mean normalization can mitigate the problem of absolute analysis data size resulting from the difference in the innate size between the analysis targets, and reduce the sensitivity of the analysis results due to extreme values by adjusting the size of each variable. The average standardization applied in this study is not the only means to refine analysis data. However, it is a useful method as the external limits of the analysis can be overcome in advance by narrowing the gaps between the data and standardizing the data 
to a comparable range while maintaining the characteristics inherent in the analysis data. Even if the mean normalized data are used in the DEA model, the same result as the efficiency score using the original data can be obtained $[23,10]$. Therefore, in the actual analysis in this study, original data were mean-normalized to evaluate the implementation level. In addition, prior to the application of the average standardization, a method of substituting the natural $\log (\ln )$ was also considered, but due to the excessive reduction in the data gaps for each local government, it was judged to be unsuitable for deriving the optimal solution because of the decimal points problem.

\subsection{Evaluation Results for Each Target}

\subsubsection{Target 11.2: Public Transport}

The evaluation results of the implementation level are shown in Table 9.

First, 11 local governments had a CCR efficiency score (TE, CRS) of 1 (100\%) based on the DEA-CCR model (Seoul, Daegu, Incheon, Gwangju, Daejeon, Sejong, Gyeonggi, Chungbuk, Jeonnam, Gyeongnam, and Jeju), and the average CCR efficiency score of the 17 local governments analyzed was 0.9619 (96.19\%). This means that there is room for $3.81 \%$ improvement in the implementation level. Local governments that scored lower than the average on CCR efficiency were Ulsan, Chungnam, Jeonbuk, and Gyeongbuk.

Second, 13 local governments had a BCC efficiency score (PTE, VRS) of 1 based on the DEA-BCC model (Seoul, Busan, Daegu, Incheon, Gwangju, Daejeon, Sejong, Gyeonggi, Gangwon, Chungbuk, Jeonnam, Gyeongnam, and Jeju). The average BCC efficiency score of the local governments was $0.9665(96.65 \%)$, showing that the room for improvement is $3.35 \%$. The local governments lower than the average were Ulsan, Chungnam, Jeonbuk, and Gyeongbuk. Therefore, we concluded that the overall level of implementation for target 11.2 is excellent across the 17 local governments.

Third, as shown in the analysis results, the difference between the CCR efficiency score and the BCC efficiency score is due to the characteristics of the DEA model. The CCR efficiency score based on the DEA-CCR model was evaluated as an efficient DMU when it approached the efficiency boundary by increasing or decreasing the amount of input and output regardless of the size of each local government, but the BCC efficiency score based on the DEA-BCC model varied in scale and returns. It is assumed that the optimal scale was not achieved. Therefore, the efficiency score calculated with the DEA-BCC model assuming variable yield for the scale was generally larger than the efficiency score calculated by the DEA-CCR model assuming a constant yield for the same size DMU.

This difference provided an important basis for deriving a scale efficiency (SE) score that could determine whether each DMU is losing efficiency. As noted above, scale efficiency means that the CCR efficiency score is divided by the BCC efficiency score; consequently, the DMU with a scale efficiency score of 1 has both a CCR and BCC efficiency score of 1 , which means that it has reached a relatively efficient frontier compared to other DMUs and is at the optimum scale level. As a result of deriving the scale efficiency score due to the characteristics of this model, a total of 11 local governments had a scale efficiency score of 1 (Seoul, Daegu, Incheon, Gwangju, Daejeon, Sejong, Gyeonggi, Chungbuk, Jeonnam, Gyeongnam, and Jeju), and these regions had a relatively superior implementation level compared to the others.

Finally, by changing the constraints of the DEA-BCC model assuming a variable return to scale, the inefficiently assessed DMUs' scale-income status can be observed. In other words, four local governments (Ulsan, South Chungcheong, North Jeolla, and North Gyeongsang provinces) were found to have an increasing return to scale when all inputs were increased by $1 \%$ or more, whereas two local governments had a decreasing return to scale (Busan and Gangwon). In general, if an increasing return to scale is assumed, an increase in output is more visible than an increase in input; in the opposite case, an increase in output is less than the increase in input, so benefits from scaling down may be considered in general $[24,9,10]$. 
Table 9. Evaluation result of the implementation level of target 11.2.

\begin{tabular}{|c|c|c|c|c|c|}
\hline & & \multicolumn{4}{|c|}{ Evaluation results } \\
\hline & & DEA-CCR & DEA-BCC & SE & Return to Scale \\
\hline 1 & Seoul & 1 & 1 & 1 & Constant \\
\hline 2 & Busan & 0.9660 & 1 & 0.9660 & Decreasing \\
\hline 3 & Daegu & 1 & 1 & 1 & Constant \\
\hline 4 & Incheon & 1 & 1 & 1 & Constant \\
\hline 5 & Gwangju & 1 & 1 & 1 & Constant \\
\hline 6 & Daejeon & 1 & 1 & 1 & Constant \\
\hline 7 & Ulsan & 0.9009 & 0.9024 & 0.9983 & Increasing \\
\hline 8 & Sejong & 1 & 1 & 1 & Constant \\
\hline 9 & Gyeonggi & 1 & 1 & 1 & Constant \\
\hline 10 & Gangwon & 0.9693 & 1 & 0.9693 & Decreasing \\
\hline 11 & Chungbuk & 1 & 1 & 1 & Constant \\
\hline 12 & Chungnam & 0.9354 & 0.9419 & 0.9930 & Increasing \\
\hline 13 & Jeonbuk & 0.7477 & 0.7495 & 0.9976 & Increasing \\
\hline 14 & Jeonnam & 1 & 1 & 1 & Constant \\
\hline 15 & Gyeongbuk & 0.8330 & 0.8374 & 0.9947 & Increasing \\
\hline 16 & Gyeongnam & 1 & 1 & 1 & Constant \\
\hline 17 & Jeju & 1 & 1 & 1 & Constant \\
\hline & Average & 0.9619 & 0.9665 & 0.9952 & \\
\hline & dard deviation & 0.0720 & 0.0720 & 0.0106 & \\
\hline & Max. & 1 & 1 & 1 & \\
\hline & Min. & 0.7477 & 0.7495 & 0.9660 & \\
\hline
\end{tabular}

Figure 4 shows the composition of the efficiency frontier for the implementation level of target 11.2. It refers to the efficiency frontier (solid line) for the input variable (y axis) and output variable ( $x$ axis) to be analyzed and the production possible set of input and output variables. Figure 4a depicts the efficiency frontier according to the DEA-CCR model. Since the DEA-CCR model assumes a constant return to scale (CRS), the shape of the efficiency frontier is shown in a direct proportion. Figure $4 \mathrm{~b}$ assumes a variable return to scale (VRS) as the efficiency frontier according to the DEA-BCC model, so the efficiency frontier is constructed in the form of $1 \%$ or more or less than a $1 \%$ input.

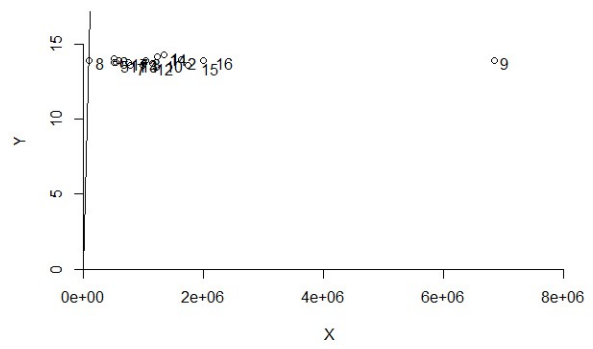

(a)

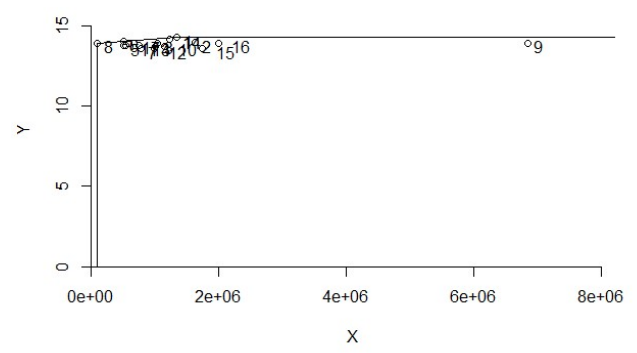

(b)

Figure 4. Constructing the efficiency frontier for the implementation level of target 11.2 (a) by the DEA-CCR model and (b) by the DEA-BCC model (1: Seoul, 2: Busan, 3: Daegu, 4: Incheon, 5: 
Gwangju, 6: Daejeon, 7: Ulsan, 8: Sejong, 9: Gyeonggi, 10: Gangwon, 11: Chungbuk, 12: Chungnam, 13: Jeonbuk, 14: Jeonnam, 15: Gyeongbuk, 16: Gyeongnam, and 17: Jeju).

In this study, by using the DEA model, it was possible to determine whether the cause of inefficiency was due to the technical defects of the input variables or due to the scale through the relationship between the BCC efficiency score and the scale efficiency score. If the BCC efficiency score is greater than the scale efficiency score, the cause of the inefficiency is regarded as a factor of scale; vice versa, the cause is regarded as a technical factor.

Table 10 demonstrates the causes of the inefficiencies of the evaluated local governments as needing to raise the implementation level from the viewpoint of efficiency by applying the characteristics of this model. As a result of the analysis, we found that the local governments whose cause of inefficiency was a scale factor were Busan and Gangwon, and the local governments whose cause of inefficiency was due to technical factors were Ulsan, Chungnam, Jeonbuk, and Gyeongbuk.

Table 10. Causes of inefficiency (target 11.2).

\begin{tabular}{cccccc}
\hline & & DEA-BCC & SE & \multicolumn{2}{c}{ Cause of inefficiency } \\
\hline & & & & Scale factor & Technical factor \\
\hline 2 & Busan & 1 & 0.9660 & $\bullet$ & \\
7 & Ulsan & 0.9024 & 0.9983 & & \\
10 & Gangwon & 1 & 0.9693 & $\bullet$ & $\bullet$ \\
12 & Chungnam & 0.9419 & 0.9930 & & $\bullet$ \\
13 & Jeonbuk & 0.7495 & 0.9976 & & $\bullet$ \\
15 & Gyeongbuk & 0.8374 & 0.9947 & & $\bullet$ \\
\hline
\end{tabular}

Note: If the BCC efficiency score is greater than the scale efficiency score, the scale factor is the cause of inefficiency; otherwise, it is regarded as a technical factor.

The time-series changes for the implementation level of target 11.2 are shown in Figure 5 .

Of the 17 local governments, Seoul maintained a scale efficiency score of 1 throughout the entire analysis period, consistently showing superior performance levels compared to the other local governments. Jeju showed the most extreme change, but we found that the implementation level was improving according to the time-series change. 


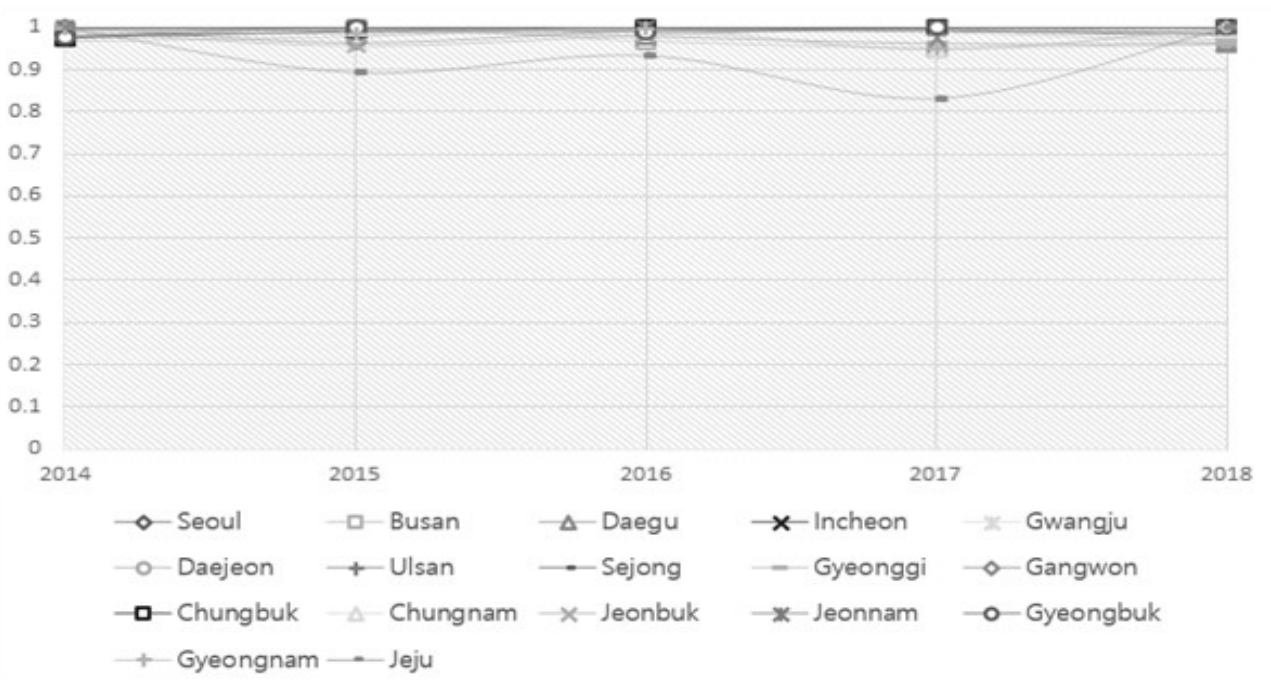

Figure 5. Changes in the implementation level of target 11.2.

\subsubsection{Target 11.5: Disaster Safety}

The evaluation results of the implementation level of target 11.5 are shown in Table 11 and Figure 6.

First, four local governments with a CCR efficiency score of 1 were identified by the DEA-CCR model (Ulsan, Sejong, Gyeongnam, and Jeju), and the average CCR efficiency score of 17 local governments was $0.6973(69.73 \%)$, indicating that there is $30.27 \%$ room for improvement. We concluded that the overall level of disaster safety was low.

Second, nine local governments had a BCC efficiency score of 1 based on the DEABCC model (Seoul, Ulsan, Sejong, Gyeonggi, Gangwon, Jeonnam, Gyeongbuk, Gyeongnam, and Jeju), and the average BCC efficiency score was 0.8701 (87.01\%). We concluded that there is room for improvement of $12.99 \%$.

Third, four local governments had a scale efficiency score of 1 (Ulsan, Sejong, Gyeongnam, and Jeju), and these regions showed relatively superior levels of implementation compared to the other regions.

Lastly, the local governments that had a constant return to scale were Ulsan, Sejong, Gyeongnam, and Jeju, and all local governments other than these regions were found to have a decreasing return to scale.

Table 11. Evaluation results of the implementation level of target 11.5.

\begin{tabular}{cccccc}
\hline & & \multicolumn{4}{c}{ Evaluation results } \\
\hline & & DEA-CCR & DEA-BCC & SE & Return to Scale \\
\hline 1 & Seoul & 0.4219 & 1 & 0.4219 & Decreasing \\
2 & Busan & 0.5212 & 0.5748 & 0.9067 & Decreasing \\
3 & Daegu & 0.4196 & 0.5488 & 0.7646 & Decreasing \\
4 & Incheon & 0.3929 & 0.6654 & 0.5905 & Decreasing \\
5 & Gwangju & 0.4112 & 0.5674 & 0.7248 & Decreasing \\
6 & Daejeon & 0.4769 & 0.5726 & 0.8336 & Decreasing \\
7 & Ulsan & 1 & 1 & 1 & Constant \\
8 & Sejong & 1 & 1 & 1 & Constant \\
9 & Gyeonggi & 0.6497 & 1 & 0.6497 & Decreasing \\
10 & Gangwon & 0.9364 & 1 & 0.9364 & Decreasing
\end{tabular}




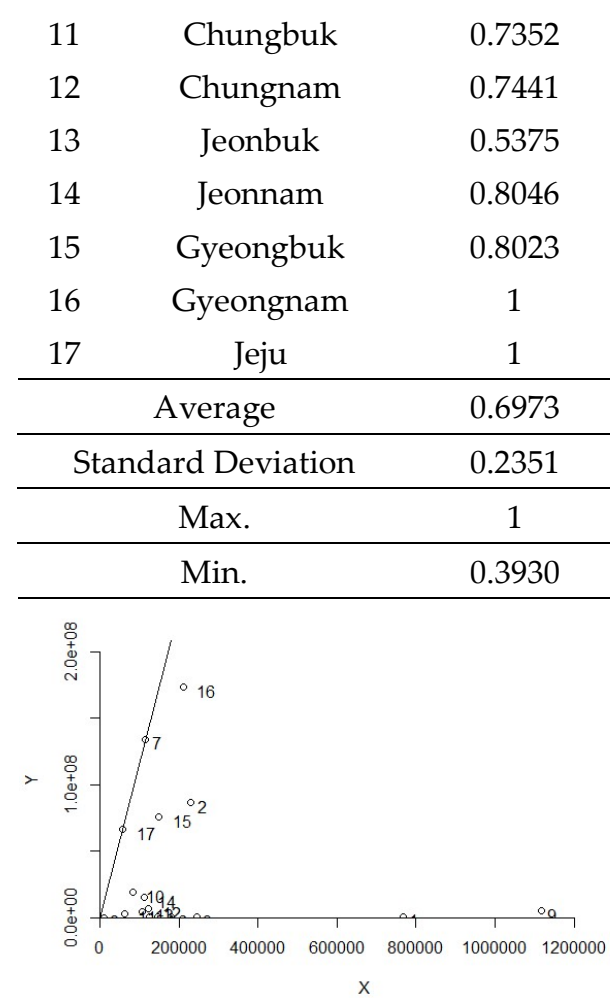

(a)

$\begin{array}{ccc}0.9345 & 0.7866 & \text { Decreasing } \\ 0.9861 & 0.7546 & \text { Decreasing } \\ 0.9426 & 0.5702 & \text { Decreasing } \\ 1 & 0.8046 & \text { Decreasing } \\ 1 & 0.8023 & \text { Decreasing } \\ 1 & 1 & \text { Constant } \\ 1 & 1 & \text { Constant }\end{array}$

$0.8701 \quad 0.796$

$0.1916 \quad 0.1700$

$\begin{array}{cc}1 & 1 \\ 0.5488 & 0.4220\end{array}$

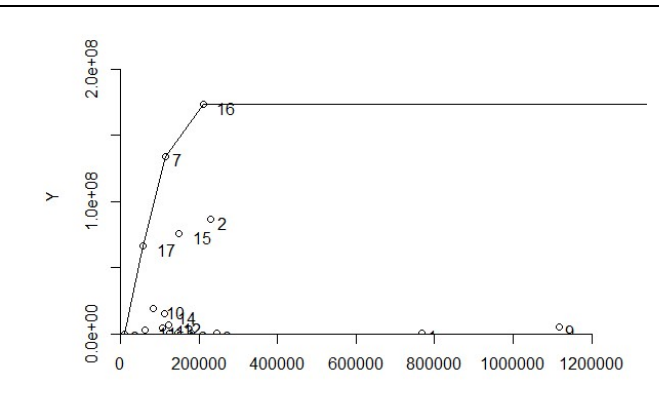

(b)

Figure 6. Construction of the efficiency frontier for the implementation level of target 11.5 (a) by the DEA-CCR model and (b) by the DEA-BCC model (1: Seoul, 2: Busan, 3: Daegu, 4: Incheon, 5: Gwangju, 6: Daejeon, 7: Ulsan, 8: Sejong, 9: Gyeonggi, 10: Gangwon, 11: Chungbuk, 12: Chungnam, 13: Jeonbuk, 14: Jeonnam, 15: Gyeongbuk, 16: Gyeongnam, and 17: Jeju).

Table 12 shows the causes of inefficiency for each local government.

Table 12. Causes of inefficiency (target 11.5).

\begin{tabular}{|c|c|c|c|c|c|}
\hline & & \multirow[t]{2}{*}{ DEA-BCC } & \multirow[t]{2}{*}{ SE } & \multicolumn{2}{|c|}{ Cause of inefficiency } \\
\hline & & & & Scale factor & Technical factor \\
\hline 2 & Busan & 0.5748 & 0.9067 & & 0 \\
\hline 3 & Daegu & 0.5488 & 0.7646 & & 0 \\
\hline 4 & Incheon & 0.6654 & 0.5905 & 0 & \\
\hline 5 & Gwanju & 0.5674 & 0.7248 & & 0 \\
\hline 6 & Daejeon & 0.5726 & 0.8336 & & 0 \\
\hline 9 & Gyeonggi & 1 & 0.6497 & 0 & \\
\hline 10 & Gangwon & 1 & 0.9364 & 0 & \\
\hline 11 & Chungbuk & 0.9345 & 0.7866 & 0 & \\
\hline 12 & Chungnam & 0.9861 & 0.7546 & 0 & \\
\hline 13 & Jeonbuk & 0.9426 & 0.5702 & 0 & \\
\hline 14 & Jeonnam & 1 & 0.8046 & 0 & \\
\hline
\end{tabular}


15 Gyeongbuk

1

0.8023

Note: If the BCC efficiency score is greater than the scale efficiency score, the scale factor is the cause of inefficiency; otherwise, the cause of inefficiency is regarded as a technical factor.

The time-series changes for the level of implementation of target 11.5 are shown in Figure 7.

As a result of the analysis, we found that there is room for improvement overall in the transition implementation level in regions except for Sejong. In particular, we found that in Seoul and Jeonbuk, which showed a low transition level according to the change in CCR efficiency score, the low level continued to be maintained throughout the entire analysis period. This is similar to characteristics of the results of the cross-sectional analysis in 2018.

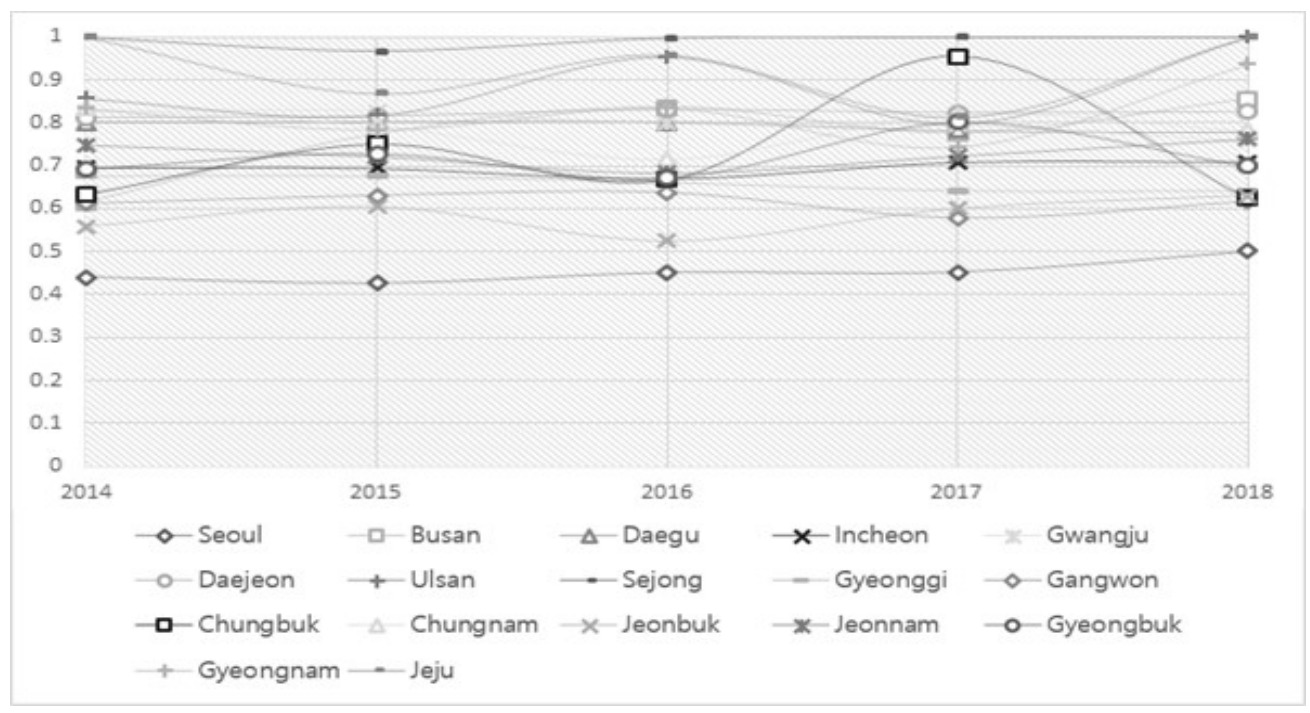

Figure 7. Changes in the implementation level of target 11.5.

\subsubsection{Target 11.6: Environment (Air Quality)}

Target 11.6 is largely divided into issues related to air quality improvement and waste management. Therefore, in this study, the composition of input and output variables and environmental variables was divided into air quality and waste management, and evaluation results are presented separately.

The evaluation results of the implementation level of target 11.6 (air quality sector) are shown in Table 13 and Figure 8.

First, three local governments received a CCR efficiency score of 1 based on the DEACCR model (Sejong, Jeonnam, and Jeju), and the average of CCR efficiency score of the 17 local governments was calculated as $0.6604(60.04 \%)$.

Second, 12 local governments received a BCC efficiency score of 1 by the DEA-BCC model (Seoul, Daegu, Incheon, Gwangju, Daejeon, Ulsan, Sejong, Gyeonggi, Gangwon, Jeonbuk, Jeonnam, and Jeju), and the average BCC efficiency score was 0.9392 (93.92\%), indicating a room for improvement of $6.08 \%$.

Third, three local governments had a scale efficiency score of 1 (Sejong, Jeonnam, and Jeju), showing relatively better performance than the other regions.

Lastly, we found that the remaining regions other than Sejong, Jeonnam, and Jeju, which appeared at the optimum scale, had a decreasing return to scale.

Table 13. Evaluation results of the implementation level of target 11.6 (air quality).

\section{Evaluation results}

DEA-CCR DEA-BCC SE Return to Scale




\begin{tabular}{lccccc}
\hline 1 & Seoul & 0.1764 & 1 & 0.1764 & Decreasing \\
2 & Busan & 0.3670 & 0.9161 & 0.4006 & Decreasing \\
3 & Daegu & 0.5086 & 1 & 0.5086 & Decreasing \\
4 & Incheon & 0.2982 & 1 & 0.2982 & Decreasing \\
5 & Gwangju & 0.5164 & 1 & 0.5164 & Decreasing \\
6 & Daejeon & 0.5632 & 1 & 0.5632 & Decreasing \\
7 & Ulsan & 0.5177 & 1 & 0.5177 & Decreasing \\
8 & Sejong & 1 & 1 & 1 & Constant \\
9 & Gyeonggi & 0.7159 & 1 & 0.7159 & Decreasing \\
10 & Gangwon & 0.7333 & 1 & 0.7333 & Decreasing \\
11 & Chungbuk & 0.7399 & 0.8237 & 0.8982 & Decreasing \\
12 & Chungnam & 0.7600 & 0.7452 & 0.9805 & Decreasing \\
13 & Jeonbuk & 0.8863 & 1 & 0.8863 & Decreasing \\
14 & Jeonnam & 1 & 1 & 1 & Constant \\
15 & Gyeongbuk & 0.7543 & 0.7743 & 0.9742 & Decreasing \\
16 & Gyeongnam & 0.6903 & 0.7067 & 0.9769 & Increasing \\
17 & Jeju & 1 & 1 & 1 & Constant \\
\hline \multicolumn{7}{r}{ Average } & 0.6604 & 0.9392 & 0.7156 & \\
\cline { 1 - 4 } Standard Deviation & 0.2445 & 0.1052 & 0.2773 & \\
\cline { 1 - 4 } & Max. & 1 & 1 & 1 & \\
\cline { 1 - 4 } & Min. & 0.1764 & 0.7067 & 0.1764 & \\
\hline
\end{tabular}

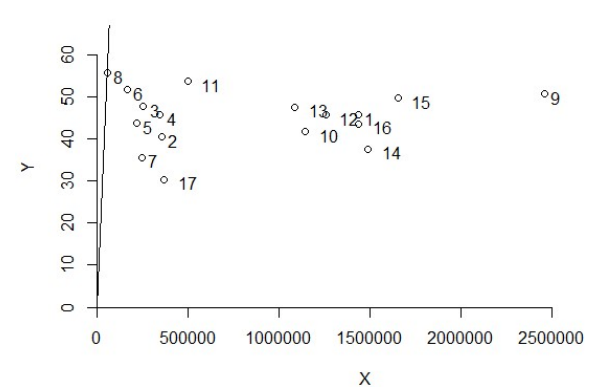

(a)

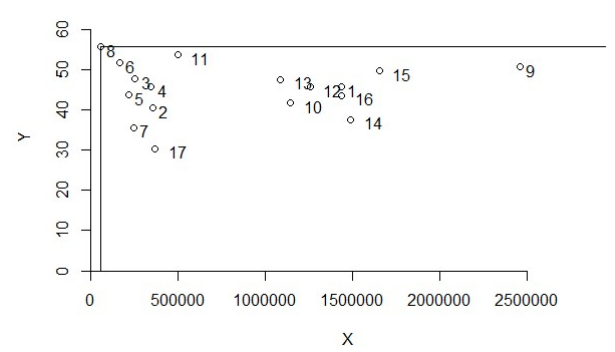

(b)

Figure 8. Constructing the efficiency frontier for the implementation level of target 11.6 (air quality) by (a) the DEA-CCR model and (b) the DEA-BCC model (1: Seoul, 2: Busan, 3: Daegu, 4: Incheon, 5: Gwangju, 6: Daejeon, 7: Ulsan, 8: Sejong, 9: Gyeonggi, 10: Gangwon, 11: Chungbuk, 12: Chungnam, 13: Jeonbuk, 14: Jeonnam, 15: Gyeongbuk, 16: Gyeongnam, and 17: Jeju).

Table 14 shows the causes of inefficiency for each local government.

Table 14. Causes of inefficiency (target 11.6 air quality).

\begin{tabular}{cccccc}
\hline & & DEA-BCC & SE & \multicolumn{2}{c}{ Cause of inefficiency } \\
\hline & & & & Scale factor & Technical factor \\
\hline 1 & Seoul & 1 & 0.1764 & $\bullet$ & \\
2 & Busan & 0.9161 & 0.4006 & $\bullet$ & \\
3 & Daegu & 1 & 0.5086 & $\bullet$
\end{tabular}




$\begin{array}{cccc}4 & \text { Incheon } & 1 & 0.2982 \\ 5 & \text { Gwangju } & 1 & 0.5164 \\ 6 & \text { Daejeon } & 1 & 0.5632 \\ 7 & \text { Ulsan } & 1 & 0.5177 \\ 9 & \text { Gyeonggi } & 1 & 0.7159 \\ 10 & \text { Gangwon } & 1 & 0.7333 \\ 11 & \text { Chungbuk } & 0.8237 & 0.8982 \\ 12 & \text { Chungnam } & 0.7452 & 0.9805 \\ 13 & \text { Jeonbuk } & 1 & 0.8863 \\ 15 & \text { Gyeongbuk } & 0.7743 & 0.9742 \\ 16 & \text { Gyeongnam } & 0.7067 & 0.9769\end{array}$

Note: If the BCC efficiency score is greater than the scale efficiency score, the scale factor is the cause of inefficiency; otherwise, it is regarded as a technical factor.

The time-series changes for the implementation level of target 11.6 (air quality) are shown in Figure 9.

As a result of the analysis, we found that Sejong showed a higher implementation level than the other regions, and Seoul and Incheon maintained a very low level compared to other local governments.

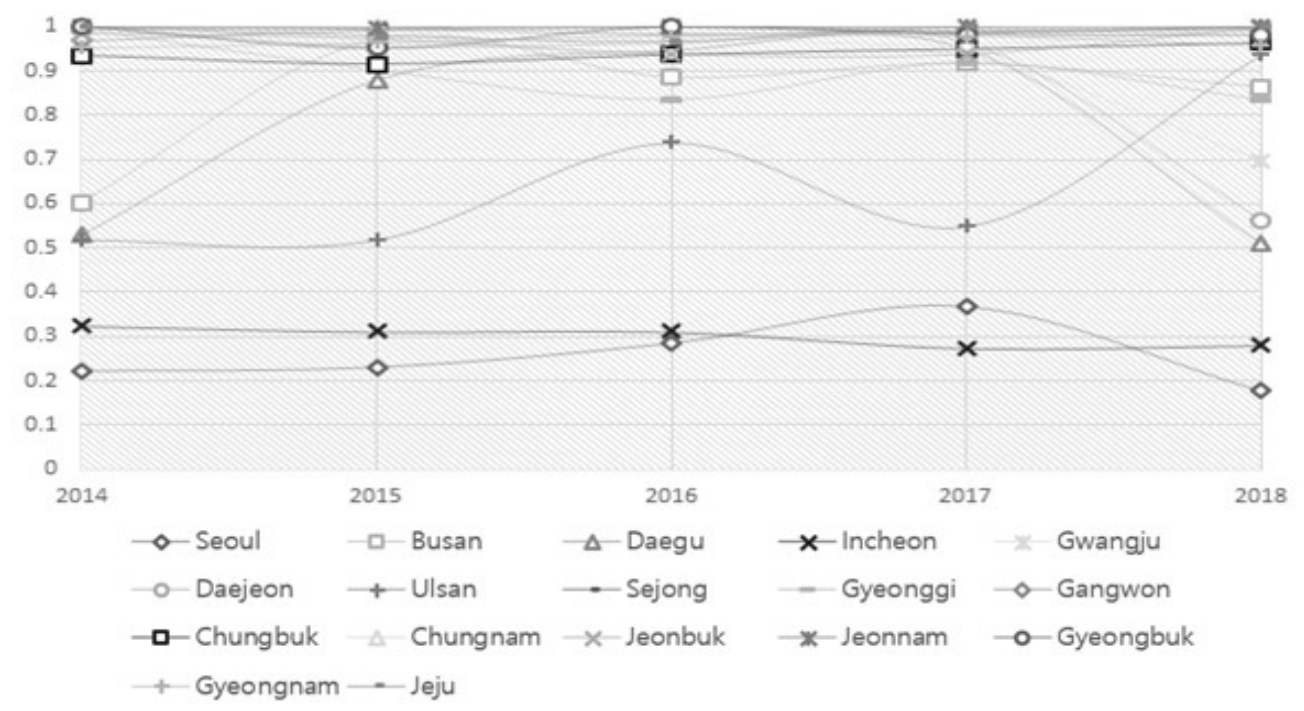

Figure 9. Changes in the implementation level of target 11.6 (air quality).

\subsubsection{Target 11.6: Environment (Waste Management)}

The evaluation results of the implementation level of the waste sector (target 11.6) are shown in Table 15 and Figure 10.

First, four local governments with a CCR efficiency score of 1 were identified based on the DEA-CCR model (Gwangju, Ulsan, Sejong, and Chungbuk), and the average CCR efficiency score of seventeen local governments was 0.7627 (76.27\%).

Second, six local governments received a BCC efficiency score of 1 (Gwangju, Ulsan, Sejong, Gyeonggi, Chungbuk, and Chungnam), and the average BCC efficiency score was $0.8313(83.13 \%)$. 
Third, four local governments with a scale efficiency score of 1 were found to have a relatively superior level of implementation compared to the other regions (Gwangju, Ulsan, Sejong, and Chungbuk).

Lastly, four areas showed an optimal scale with a scale efficiency score of 1: Gwangju, Ulsan, Sejong, and Chungbuk.

Table 15. Evaluation result of the implementation level of target 11.6 (waste management).

\begin{tabular}{|c|c|c|c|c|c|}
\hline & & \multicolumn{4}{|c|}{ Evaluation results } \\
\hline & & DEA-CCR & DEA-BCC & SE & Return to Scale \\
\hline 1 & Seoul & 0.6125 & 0.8998 & 0.6807 & Decreasing \\
\hline 2 & Busan & 0.2084 & 0.2756 & 0.7562 & Decreasing \\
\hline 3 & Daegu & 0.6745 & 0.6901 & 0.9775 & Decreasing \\
\hline 4 & Incheon & 0.7545 & 0.7552 & 0.9991 & Increasing \\
\hline 5 & Gwangju & 1 & 1 & 1 & Constant \\
\hline 6 & Daejeon & 0.6851 & 0.7076 & 0.9682 & Increasing \\
\hline 7 & Ulsan & 1 & 1 & 1 & Constant \\
\hline 8 & Sejong & 1 & 1 & 1 & Constant \\
\hline 9 & Gyeonggi & 0.7027 & 1 & 0.7027 & Decreasing \\
\hline 10 & Gangwon & 0.6532 & 0.6548 & 0.9975 & Increasing \\
\hline 11 & Chungbuk & 1 & 1 & 1 & Constant \\
\hline 12 & Chungnam & 0.9744 & 1 & 0.9744 & Decreasing \\
\hline 13 & Jeonbuk & 0.5862 & 0.6284 & 0.9328 & Decreasing \\
\hline 14 & Jeonnam & 0.7994 & 0.8007 & 0.9983 & Increasing \\
\hline 15 & Gyeongbuk & 0.8269 & 0.9557 & 0.8652 & Decreasing \\
\hline 16 & Gyeongnam & 0.7042 & 0.9578 & 0.7353 & Decreasing \\
\hline 17 & Jeju & 0.7842 & 0.8064 & 0.9725 & Decreasing \\
\hline & Average & 0.7627 & 0.8313 & 0.9153 & \\
\hline Stan & ard Deviation & 0.2046 & 0.1985 & 0.1182 & \\
\hline & Max. & 1.0000 & 1.0000 & 1.0000 & \\
\hline & Min. & 0.2084 & 0.2756 & 0.6807 & \\
\hline
\end{tabular}

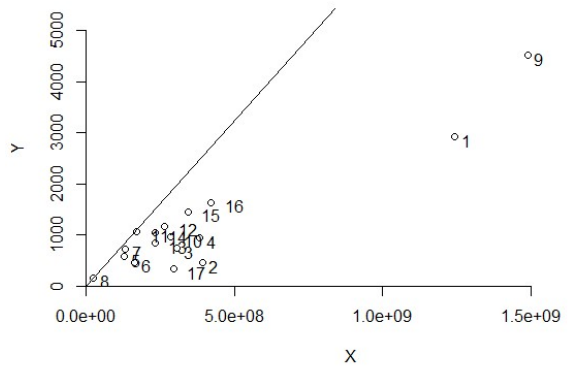

(a)

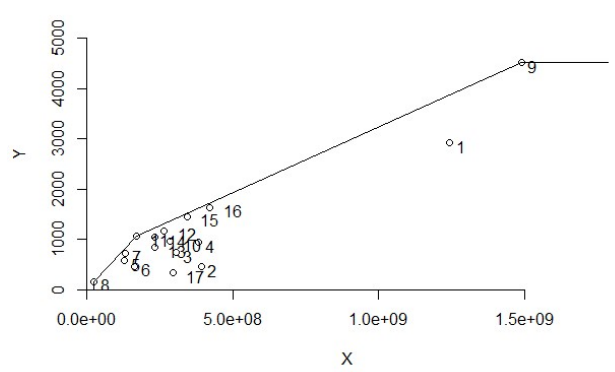

(b)

Figure 10. Constructing the efficiency frontier for the implementation level of target 11.6 (waste management) by (a) the DEA-CCR model and (b) the DEA-BCC model (1: Seoul, 2: Busan, 3: Daegu, 4: Incheon, 5: Gwangju, 6: Daejeon, 7: Ulsan, 8: Sejong, 9: Gyeonggi, 10: Gangwon, 11: Chungbuk, 12: Chungnam, 13: Jeonbuk, 14: Jeonnam, 15: Gyeongbuk, 16: Gyeongnam, and 17: Jeju). 
Table 16 shows the causes of inefficiency for each local government. As a result of the analysis, the local governments whose cause of inefficiency was a scale factor were Seoul, Gyeonggi, Chungnam, Gyeongbuk, and Gyeongnam, and local governments whose cause of inefficiency was a technical factor were Busan, Daegu, Incheon, Gangwon, Jeonbuk, Jeonnam, and Jeju.

Table 16. Causes of inefficiency (target 11.6, waste management).

\begin{tabular}{cccccc}
\hline & & DEA-BCC & SE & \multicolumn{2}{c}{ Cause of inefficiency } \\
\hline 1 & Seoul & 0.8998 & 0.6807 & Scale factor & Technical factor \\
2 & Busan & 0.2756 & 0.7562 & & \\
3 & Daegu & 0.6901 & 0.9775 & & \\
4 & Incheon & 0.7552 & 0.9991 & \\
6 & Daejeon & 0.7076 & 0.9682 & & \\
9 & Gyeonggi & 1 & 0.7027 & & \\
10 & Gangwon & 0.6548 & 0.9975 & & \\
12 & Chungnam & 1 & 0.9744 & & \\
13 & Jeonbuk & 0.6284 & 0.9328 & \\
14 & Jeonnam & 0.8007 & 0.9983 & \\
15 & Gyeongbuk & 0.9557 & 0.8652 & & \\
16 & Gyeongnam & 0.9578 & 0.7353 & 0.9725 & \\
17 & Jeju & 0.8064 & & \\
\hline
\end{tabular}

Note: If the BCC efficiency score is greater than the scale efficiency score, the scale factor is the cause of inefficiency; otherwise, the cause is regarded as a technical factor.

The time-series changes for the implementation level of target 11.6 (waste management) are shown in Figure 11. As a result of the analysis, it was found that Ulsan, Sejong, and Gangwon showed a higher implementation level than the other regions.

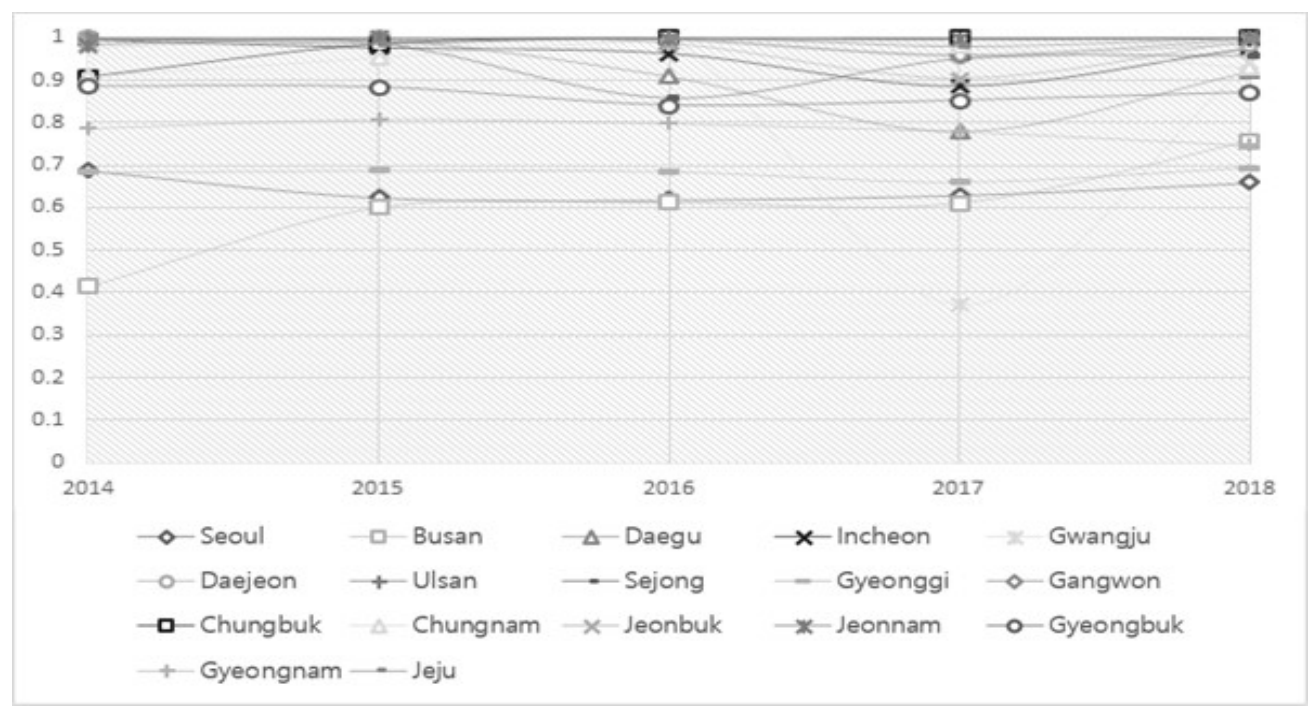


Figure 11. Changes in the implementation level of target 11.6 (waste management).

\subsubsection{Target 11.7: Public Space}

The evaluation results of the implementation level of target 11.7 are shown in Table 17 and Figure 12.

First, three local governments had a CCR efficiency score of 1 according to the DEACCR model (Seoul, Sejong, and Gyeonggi), and the average CCR efficiency score of seventeen local governments was 0.6107 (61.07\%), indicating 38.93\% room for improvement.

Second, three local governments had a BCC efficiency score of 1 per the DEA-BCC model (Seoul, Sejong, and Gyeonggi), and the average BCC efficiency score was 0.7044 (70.44\%), indicating $29.56 \%$ room for improvement.

Third, three local governments received a scale efficiency score of 1 (Seoul, Sejong, and Gyeonggi), showing relatively better performance than the other regions.

Lastly, the local governments that showed an optimal scale with a scale efficiency score of 1 were Seoul, Sejong, and Gyeonggi.

Table 17. Evaluation result of the implementation level of target 11.7 (public space).

\begin{tabular}{|c|c|c|c|c|c|}
\hline & & \multicolumn{4}{|c|}{ Evaluation results } \\
\hline & & DEA-CCR & DEA-BCC & SE & Return to Scale \\
\hline 1 & Seoul & 1 & 1 & 1 & Constant \\
\hline 2 & Busan & 0.5066 & 0.5237 & 0.9674 & Decreasing \\
\hline 3 & Daegu & 0.4506 & 0.5533 & 0.8145 & Increasing \\
\hline 4 & Incheon & 0.6349 & 0.6511 & 0.9751 & Increasing \\
\hline 5 & Gwangju & 0.2663 & 0.3617 & 0.7364 & Increasing \\
\hline 6 & Daejeon & 0.6221 & 0.6486 & 0.9592 & Increasing \\
\hline 7 & Ulsan & 0.7452 & 0.7987 & 0.9331 & Increasing \\
\hline 8 & Sejong & 1 & 1 & 1 & Constant \\
\hline 9 & Gyeonggi & 1 & 1 & 1 & Constant \\
\hline 10 & Gangwon & 0.4259 & 0.6221 & 0.6847 & Increasing \\
\hline 11 & Chungbuk & 0.4632 & 0.6033 & 0.7678 & Increasing \\
\hline 12 & Chungnam & 0.3180 & 0.4389 & 0.7244 & Increasing \\
\hline 13 & Jeonbuk & 0.4703 & 0.5389 & 0.8727 & Increasing \\
\hline 14 & Jeonnam & 0.7513 & 0.9062 & 0.8290 & Increasing \\
\hline 15 & Gyeongbuk & 0.6451 & 0.7524 & 0.8574 & Increasing \\
\hline 16 & Gyeongnam & 0.8506 & 0.9088 & 0.9360 & Increasing \\
\hline 17 & Jeju & 0.2325 & 0.6667 & 0.3487 & Increasing \\
\hline & Average & 0.6107 & 0.7044 & 0.8474 & \\
\hline Sta & ard Deviation & 0.2514 & 0.2017 & 0.1657 & \\
\hline & Max. & 1.0000 & 1.0000 & 1.0000 & \\
\hline & Min. & 0.2325 & 0.3617 & 0.3487 & \\
\hline
\end{tabular}




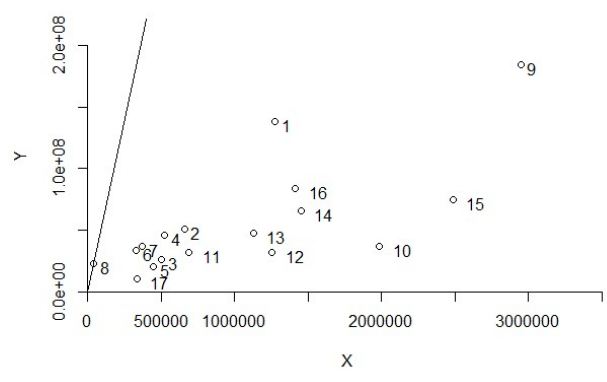

(a)

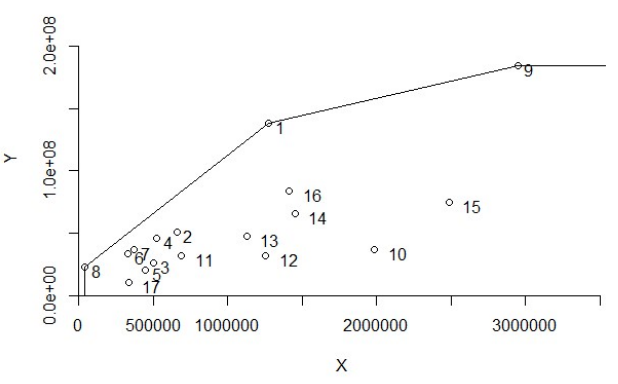

(b)

Figure 12. Constructing the efficiency frontier for the implementation level of target 11.7 by (a) the DEA-CCR model and (b) the DEA-BCC model (1: Seoul, 2: Busan, 3: Daegu, 4: Incheon, 5: Gwangju, 6: Daejeon, 7: Ulsan, 8: Sejong, 9: Gyeonggi, 10: Gangwon, 11: Chungbuk, 12: Chungnam, 13: Jeonbuk, 14: Jeonnam, 15: Gyeongbuk, 16: Gyeongnam, and 17: Jeju).

Table 18 shows the causes of inefficiency for each local government.

Table 18. Causes of inefficiency (target 11.7, public space).

\begin{tabular}{|c|c|c|c|c|c|}
\hline & & \multirow[t]{2}{*}{ DEA-BCC } & \multirow[t]{2}{*}{ SE } & \multicolumn{2}{|c|}{ Cause of inefficiency } \\
\hline & & & & Scale factor & Technical factor \\
\hline 2 & Busan & 0.5237 & 0.9674 & & 0 \\
\hline 3 & Daegu & 0.5533 & 0.8145 & & 0 \\
\hline 4 & Incheon & 0.6511 & 0.9751 & & 0 \\
\hline 5 & Gwangju & 0.3617 & 0.7364 & & 0 \\
\hline 6 & Daejeon & 0.6486 & 0.9592 & & 0 \\
\hline 7 & Ulsan & 0.7987 & 0.9331 & & 0 \\
\hline 10 & Gangwon & 0.6221 & 0.6847 & & 0 \\
\hline 11 & Chungbuk & 0.6033 & 0.7678 & & 0 \\
\hline 12 & Chungnam & 0.4389 & 0.7244 & & 0 \\
\hline 13 & Jeonbuk & 0.5389 & 0.8727 & & 0 \\
\hline 14 & Jeonnam & 0.9062 & 0.8290 & 0 & \\
\hline 15 & Gyeongbuk & 0.7524 & 0.8574 & & 0 \\
\hline 16 & Gyeongnam & 0.9088 & 0.9360 & & 0 \\
\hline 17 & Jeju & 0.6667 & 0.3487 & 0 & \\
\hline
\end{tabular}

Note: If the BCC efficiency score is greater than the scale efficiency score, the scale factor is the cause of inefficiency; otherwise, the cause is regarded as a technical factor.

The time-series changes for the level of implementation of target 11.7 are shown in Figure 13. As a result of the analysis, we found that Seoul, Sejong, and Gyeonggi showed a higher level of implementation than the other regions. 


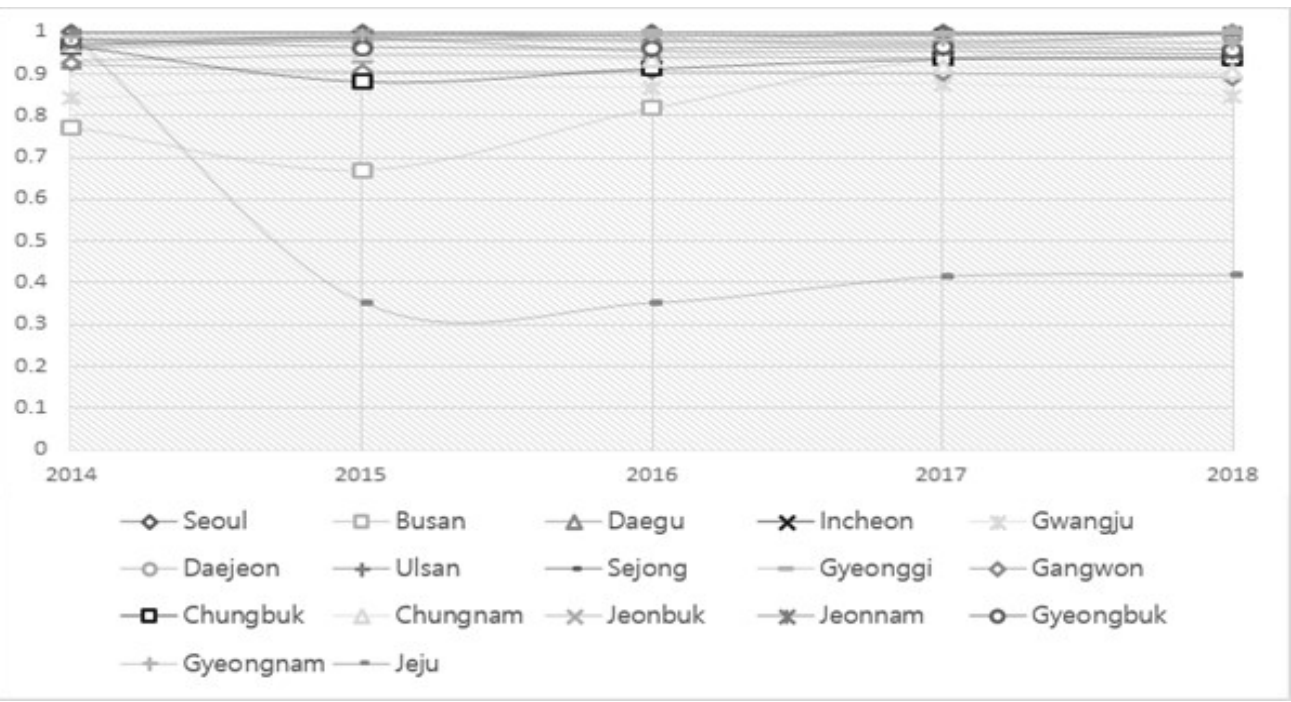

Figure 13. Changes in the implementation level of target 11.7 (public space).

\subsection{Application of Bootstrapping DEA Model}

The advantage of the standard DEA model is that efficiency analysis is possible even when there are multiple input and output variables, and the weight of each variable is determined within the model; moreover, it is free in terms of the unit of the analyzed variable. However, since it is a non-parametric model, it is difficult to check the random errors implied in the calculated efficiency score, and the model has limitations, such as the efficiency score is inflated. Therefore, in order to mitigate the impact of the model's limitations on the influencing factors' analysis, a bootstrapping DEA model was applied to the efficiency scores previously derived by the DEA model and used as a dependent variable of the two-stage approach by estimating the efficiency score with adjusted bias.

In this study, the dependent variable was derived by applying the bootstrapping DEA model to the BCC efficiency score (2000 iterations). The reason for using only the BCC efficiency score and not the CCR efficiency score is that the BCC efficiency score assumes variable scale returns, whereas the CCR efficiency score assumes constant scale returns. Therefore, the BCC efficiency score can be used to produce more realistic analysis results and implications because it has more universality that maintains the consistency of the efficiency boundary $[25,26]$.

\subsubsection{Target 11.2: Public Transport}

Table 19 shows the results analysis of the efficiency score with adjusted bias and the $95 \%$ confidence intervals obtained by applying the bootstrapping DEA model to remove the bias of the BCC efficiency score based on the cross-section in 2018. As a result of removing the bias, we found that the scores were all less than one, which is lower than the efficiency score of the standard model.

Considering the implementation level of target 11.2 through this process, the implementation level in Incheon was found to be $0.9762(97.62 \%)$, showing a relatively excellent implementation level. We determined that the level of improvement in Jeonbuk was $0.7375(73.75 \%)$.

Table 19. Performance level of evaluation results with bias adjustment (target 11.2).

\begin{tabular}{|c|c|c|c|c|c|c|c|}
\hline & & \multirow[t]{2}{*}{$\begin{array}{c}\text { Efficiency score } \\
\text { (PTE, VRS) }\end{array}$} & \multirow[t]{2}{*}{ Bias } & \multirow[t]{2}{*}{$\begin{array}{c}\text { Efficiency score } \\
\text { with adjusted bias }\end{array}$} & \multirow[t]{2}{*}{$\begin{array}{l}\text { Standard } \\
\text { deviation }\end{array}$} & \multicolumn{2}{|c|}{$95 \%$ confidence interval } \\
\hline & & & & & & Lower & Upper \\
\hline 1 & Seoul & 1.0000 & 0.0478 & 0.9522 & 0.0791 & 0.9058 & 1.2286 \\
\hline
\end{tabular}




\begin{tabular}{|c|c|c|c|c|c|c|c|}
\hline 2 & Busan & 1.0000 & 0.0482 & 0.9518 & 0.0779 & 0.9049 & 1.2066 \\
\hline 3 & Daegu & 1.0000 & 0.0515 & 0.9485 & 0.0837 & 0.8986 & 1.2027 \\
\hline 4 & Incheon & 1.0000 & 0.0238 & 0.9762 & 0.0226 & 0.9536 & 1.0347 \\
\hline 5 & Gwangju & 1.0000 & 0.0484 & 0.9516 & 0.0796 & 0.9048 & 1.2265 \\
\hline 6 & Daejeon & 1.0000 & 0.0542 & 0.9458 & 0.0867 & 0.8930 & 1.2235 \\
\hline 7 & Ulsan & 0.9024 & 0.0146 & 0.8879 & 0.0187 & 0.8745 & 0.9508 \\
\hline 8 & Sejong & 1.0000 & 0.0521 & 0.9479 & 0.0830 & 0.8972 & 1.2194 \\
\hline 9 & Gyeonggi & 1.0000 & 0.0430 & 0.9570 & 0.0611 & 0.9154 & 1.1197 \\
\hline 10 & Gangwon & 1.0000 & 0.0511 & 0.9489 & 0.0842 & 0.8992 & 1.2278 \\
\hline 11 & Chungbuk & 1.0000 & 0.0321 & 0.9679 & 0.0403 & 0.9373 & 1.0748 \\
\hline 12 & Chungnam & 0.9419 & 0.0110 & 0.9309 & 0.0084 & 0.9213 & 0.9491 \\
\hline 13 & Jeonbuk & 0.7495 & 0.0120 & 0.7375 & 0.0162 & 0.7267 & 0.7840 \\
\hline 14 & Jeonnam & 1.0000 & 0.0506 & 0.9494 & 0.0815 & 0.9003 & 1.2212 \\
\hline 15 & Gyeongbuk & 0.8374 & 0.0111 & 0.8263 & 0.0104 & 0.8163 & 0.8579 \\
\hline 16 & Gyeongnam & 1.0000 & 0.0463 & 0.9537 & 0.0679 & 0.9087 & 1.1383 \\
\hline 17 & Jeju & 1.0000 & 0.0386 & 0.9614 & 0.0540 & 0.9244 & 1.1200 \\
\hline & Average & 0.9665 & 0.0374 & 0.9291 & 0.0562 & 0.8931 & 1.1050 \\
\hline Sta & dard Deviation & 0.0720 & 0.0164 & 0.0605 & 0.0299 & 0.0516 & 0.1426 \\
\hline & Max. & 1.0000 & 0.0542 & 0.9762 & 0.0867 & 0.9536 & 1.2286 \\
\hline & Min. & 0.7495 & 0.0110 & 0.7375 & 0.0084 & 0.7267 & 0.7840 \\
\hline
\end{tabular}

\subsubsection{Target 11.5: Disaster Safety}

Table 20 shows the evaluation results of the implementation level adjusted for the bias of target 11.5. Considering the analysis results, we found that the implementation level in Chungnam was 0.9422 (94.22\%), which was the best implementation level. Conversely, the level in Daegu was 0.5240 (52.40\%), indicating that it is necessary to apply measures to improve the implementation level.

Table 20. Performance level of the evaluation results with bias adjustment (target 11.5).

\begin{tabular}{cccccccc}
\hline & & $\begin{array}{c}\text { Efficiency score } \\
\text { (PTE, VRS) }\end{array}$ & Bias & $\begin{array}{c}\text { Efficiency score } \\
\text { with adjusted bias }\end{array}$ & $\begin{array}{c}\text { Standard } \\
\text { deviation }\end{array}$ & 95\% Confidence interval \\
\hline & & & & & Lower & Upper \\
\hline 1 & Seoul & 1.0000 & 0.1339 & 0.8661 & 0.1937 & 0.7371 & 1.5034 \\
2 & Busan & 0.5749 & 0.0380 & 0.5369 & 0.0512 & 0.5016 & 0.6990 \\
3 & Daegu & 0.5488 & 0.0248 & 0.5240 & 0.0172 & 0.5020 & 0.6186 \\
4 & Incheon & 0.6655 & 0.0253 & 0.6401 & 0.0169 & 0.5680 & 0.5044 \\
5 & Gwangju & 0.5674 & 0.0331 & 0.5343 & 0.0324 & 0.5162 & 0.5361 \\
6 & Daejeon & 0.5726 & 0.0296 & 0.5430 & 0.3072 & 0.6158 \\
7 & Ulsan & 1.0000 & 0.2349 & 0.7651 & 0.3047 & 0.5473 \\
8 & Sejong & 1.0000 & 0.2290 & 0.7710 & 0.3024 & 0.5420 & 1.3940 \\
9 & Gyeonggi & 1.0000 & 0.2316 & 0.7684 & 0.1634 & 0.7154 \\
10 & Gangwon & 1.0000 & 0.1449 & 0.8551 & 0.0785 & 0.8223 & 1.3820 \\
11 & Chungbuk & 0.9346 & 0.0586 & 0.8760 & 0.0463 & 0.9036
\end{tabular}




\begin{tabular}{|c|c|c|c|c|c|c|c|}
\hline 13 & Jeonbuk & 0.9427 & 0.0418 & 0.9009 & 0.0380 & 0.8641 & 1.0110 \\
\hline 14 & Jeonnam & 1.0000 & 0.1196 & 0.8804 & 0.1380 & 0.7660 & 1.2584 \\
\hline 15 & Gyeongbuk & 1.0000 & 0.1457 & 0.8543 & 0.1758 & 0.7137 & 1.3010 \\
\hline 16 & Gyeongnam & 1.0000 & 0.2508 & 0.7492 & 0.3144 & 0.5036 & 1.3602 \\
\hline 17 & Jeju & 1.0000 & 0.1305 & 0.8695 & 0.1705 & 0.7446 & 1.3858 \\
\hline & Average & 0.8701 & 0.1127 & 0.7574 & 0.1398 & 0.6493 & 1.0947 \\
\hline Sta & dard Deviation & 0.1916 & 0.0835 & 0.1458 & 0.1127 & 0.1412 & 0.3289 \\
\hline & Max. & 1.0000 & 0.2508 & 0.9422 & 0.3144 & 0.9036 & 1.5034 \\
\hline & Min. & 0.5488 & 0.0248 & 0.5240 & 0.0169 & 0.5016 & 0.5680 \\
\hline
\end{tabular}

\subsubsection{Target 11.6: Environment (Air Quality)}

The results of the assessment of the implementation level adjusted for bias in the air quality sector of target 11.6 are shown in Table 21. The results show that the implementation level of Gangwon was $0.9969(99.69 \%)$, which is a relatively superior level of implementation among the 17 local governments, and the lowest implementation level was $0.7045(70.45 \%)$, for Gyeongnam.

Table 21. Performance level of the evaluation results with bias adjustment (target 11.6, air quality).

\begin{tabular}{|c|c|c|c|c|c|c|c|}
\hline & & \multirow[t]{2}{*}{$\begin{array}{c}\text { Efficiency score } \\
\text { (PTE, VRS) }\end{array}$} & \multirow[t]{2}{*}{ Bias } & \multirow[t]{2}{*}{$\begin{array}{c}\text { Efficiency score } \\
\text { with adjusted bias }\end{array}$} & \multirow[t]{2}{*}{$\begin{array}{l}\text { Standard } \\
\text { deviation }\end{array}$} & \multicolumn{2}{|c|}{$95 \%$ Confidence interval } \\
\hline & & & & & & Lower & Upper \\
\hline 1 & Seoul & 1.0000 & 0.0065 & 0.9935 & 0.0131 & 0.9871 & 1.0436 \\
\hline 2 & Busan & 0.9161 & 0.0022 & 0.9139 & 0.0019 & 0.9917 & 0.9983 \\
\hline 3 & Daegu & 1.0000 & 0.0063 & 0.9937 & 0.0128 & 0.9876 & 1.0442 \\
\hline 4 & Incheon & 1.0000 & 0.0063 & 0.9937 & 0.0129 & 0.9875 & 1.0444 \\
\hline 5 & Gwangju & 1.0000 & 0.0034 & 0.9966 & 0.0032 & 0.9934 & 1.0047 \\
\hline 6 & Daejeon & 1.0000 & 0.0043 & 0.9957 & 0.0056 & 0.9916 & 1.0074 \\
\hline 7 & Ulsan & 1.0000 & 0.0048 & 0.9952 & 0.0070 & 0.9906 & 1.0187 \\
\hline 8 & Sejong & 1.0000 & 0.0060 & 0.9940 & 0.0125 & 0.9882 & 1.0447 \\
\hline 9 & Gyeonggi & 1.0000 & 0.0063 & 0.9937 & 0.0128 & 0.9876 & 1.0438 \\
\hline 10 & Gangwon & 1.0000 & 0.0031 & 0.9969 & 0.0025 & 0.9940 & 1.0022 \\
\hline 11 & Chungbuk & 0.8237 & 0.0018 & 0.8219 & 0.0023 & 0.9965 & 1.0017 \\
\hline 12 & Chungnam & 0.7452 & 0.0018 & 0.7434 & 0.0022 & 0.9966 & 1.0016 \\
\hline 13 & Jeonbuk & 1.0000 & 0.0054 & 0.9946 & 0.0088 & 0.9895 & 1.0252 \\
\hline 14 & Jeonnam & 1.0000 & 0.0061 & 0.9939 & 0.0122 & 0.9880 & 1.0435 \\
\hline 15 & Gyeongbuk & 0.7743 & 0.0022 & 0.7721 & 0.0025 & 0.9817 & 0.9885 \\
\hline 16 & Gyeongnam & 0.7067 & 0.0022 & 0.7045 & 0.0022 & 0.9415 & 0.9479 \\
\hline \multirow[t]{2}{*}{17} & Jeju & 1.0000 & 0.0064 & 0.9936 & 0.0128 & 0.9873 & 1.0434 \\
\hline & Average & 0.9392 & 0.0044 & 0.9348 & 0.0075 & 0.9871 & 1.0179 \\
\hline \multicolumn{2}{|c|}{ Standard Deviation } & 0.1052 & 0.0019 & 0.1037 & 0.0049 & 0.0123 & 0.0274 \\
\hline & Max. & 1.0000 & 0.0065 & 0.9969 & 0.0131 & 0.9966 & 1.0447 \\
\hline & Min. & 0.7067 & 0.0018 & 0.7045 & 0.0019 & 0.9415 & 0.9479 \\
\hline
\end{tabular}


The evaluation results of the implementation level adjusted for bias in the waste management sector of target 11.6 are shown in Table 22. The result of the analysis shows that the implementation level of Chungnam was 0.9190 (91.90\%), which is a relatively excellent level of implementation among the 17 local governments, whereas the implementation level of Busan was 0.2453 (24.53\%), the lowest amongst the local governments.

Table 22. Performance level of evaluation results with bias adjustment (target 11.6, waste management).

\begin{tabular}{|c|c|c|c|c|c|c|c|}
\hline & & \multirow[t]{2}{*}{$\begin{array}{c}\text { Efficiency score } \\
\text { (PTE, VRS) }\end{array}$} & \multirow[t]{2}{*}{ Bias } & \multirow[t]{2}{*}{$\begin{array}{c}\text { Efficiency score } \\
\text { with adjusted bias }\end{array}$} & \multirow[t]{2}{*}{$\begin{array}{l}\text { Standard } \\
\text { deviation }\end{array}$} & \multicolumn{2}{|c|}{$95 \%$ Confidence interval } \\
\hline & & & & & & Lower & Upper \\
\hline 1 & Seoul & 1.0000 & 0.0065 & 0.9935 & 0.0131 & 0.9871 & 1.0436 \\
\hline 2 & Busan & 0.9161 & 0.0022 & 0.9139 & 0.0019 & 0.9917 & 0.9983 \\
\hline 3 & Daegu & 1.0000 & 0.0063 & 0.9937 & 0.0128 & 0.9876 & 1.0442 \\
\hline 4 & Incheon & 1.0000 & 0.0063 & 0.9937 & 0.0129 & 0.9875 & 1.0444 \\
\hline 5 & Gwangju & 1.0000 & 0.0034 & 0.9966 & 0.0032 & 0.9934 & 1.0047 \\
\hline 6 & Daejeon & 1.0000 & 0.0043 & 0.9957 & 0.0056 & 0.9916 & 1.0074 \\
\hline 7 & Ulsan & 1.0000 & 0.0048 & 0.9952 & 0.0070 & 0.9906 & 1.0187 \\
\hline 8 & Sejong & 1.0000 & 0.0060 & 0.9940 & 0.0125 & 0.9882 & 1.0447 \\
\hline 9 & Gyeonggi & 1.0000 & 0.0063 & 0.9937 & 0.0128 & 0.9876 & 1.0438 \\
\hline 10 & Gangwon & 1.0000 & 0.0031 & 0.9969 & 0.0025 & 0.9940 & 1.0022 \\
\hline 11 & Chungbuk & 0.8237 & 0.0018 & 0.8219 & 0.0023 & 0.9965 & 1.0017 \\
\hline 12 & Chungnam & 0.7452 & 0.0018 & 0.7434 & 0.0022 & 0.9966 & 1.0016 \\
\hline 13 & Jeonbuk & 1.0000 & 0.0054 & 0.9946 & 0.0088 & 0.9895 & 1.0252 \\
\hline 14 & Jeonnam & 1.0000 & 0.0061 & 0.9939 & 0.0122 & 0.9880 & 1.0435 \\
\hline 15 & Gyeongbuk & 0.7743 & 0.0022 & 0.7721 & 0.0025 & 0.9817 & 0.9885 \\
\hline 16 & Gyeongnam & 0.7067 & 0.0022 & 0.7045 & 0.0022 & 0.9415 & 0.9479 \\
\hline 17 & Jeju & 1.0000 & 0.0064 & 0.9936 & 0.0128 & 0.9873 & 1.0434 \\
\hline & Average & 0.9392 & 0.0044 & 0.9348 & 0.0075 & 0.9871 & 1.0179 \\
\hline & dard Deviation & 0.1052 & 0.0019 & 0.1037 & 0.0049 & 0.0123 & 0.0274 \\
\hline & Max. & 1.0000 & 0.0065 & 0.9969 & 0.0131 & 0.9966 & 1.0447 \\
\hline & Min. & 0.7067 & 0.0018 & 0.7045 & 0.0019 & 0.9415 & 0.9479 \\
\hline
\end{tabular}

\subsubsection{Target 11.7: Public Space}

Table 23 shows the evaluation results of the implementation level adjusted for bias of target 11.7. From the analysis results, we found that the transition level in Jeonnam was $0.8058(80.58 \%)$, which is an excellent level of implementation, whereas in Gwangju, the level $(0.2818,28.18 \%)$ was relatively low, indicating that there is room for improvement.

Table 23. Performance level of the evaluation result with bias adjustment (target 11.7, public space).

\begin{tabular}{cccccccc}
\hline & & $\begin{array}{c}\text { Efficiency score } \\
\text { (PTE, VRS) }\end{array}$ & Bias & $\begin{array}{c}\text { Efficiency score } \\
\text { with adjusted bias }\end{array}$ & $\begin{array}{c}\text { Standard } \\
\text { deviation }\end{array}$ & 95\% Confidence interval \\
\hline & & & & & Lower & Upper \\
\hline 1 & Seoul & 1.0000 & 0.5066 & 0.4934 & 0.4002 & 0.0014 & 1.5751 \\
2 & Busan & 0.5237 & 0.1444 & 0.3793 & 0.1163 & 0.2418 & 0.6356 \\
3 & Daegu & 0.5533 & 0.1298 & 0.4235 & 0.1109 & 0.3008 & 0.6598
\end{tabular}




\begin{tabular}{lcllllll}
4 & Incheon & 0.6511 & 0.1550 & 0.4961 & 0.1117 & 0.3498 & 0.7355 \\
5 & Gwangju & 0.3617 & 0.0799 & 0.2818 & 0.0664 & 0.2057 & 0.4263 \\
6 & Daejeon & 0.6486 & 0.1158 & 0.5328 & 0.0884 & 0.4265 & 0.7557 \\
7 & Ulsan & 0.7987 & 0.1063 & 0.6923 & 0.0840 & 0.5969 & 0.9156 \\
8 & Sejong & 1.0000 & 0.5529 & 0.4471 & 0.4455 & 0.0914 & 1.6042 \\
9 & Gyeonggi & 1.0000 & 0.5548 & 0.4452 & 0.4572 & 0.0950 & 1.6427 \\
10 & Gangwon & 0.6221 & 0.0412 & 0.5809 & 0.0332 & 0.5469 & 0.6724 \\
11 & Chungbuk & 0.6033 & 0.0543 & 0.5490 & 0.0430 & 0.5021 & 0.6690 \\
12 & Chungnam & 0.4389 & 0.0503 & 0.3886 & 0.0405 & 0.3437 & 0.4829 \\
13 & Jeonbuk & 0.5389 & 0.0564 & 0.4825 & 0.0400 & 0.4336 & 0.5909 \\
14 & Jeonnam & 0.9062 & 0.1004 & 0.8058 & 0.0890 & 0.7174 & 1.0603 \\
15 & Gyeongbuk & 0.7524 & 0.1228 & 0.6296 & 0.1013 & 0.5168 & 0.8873 \\
16 & Gyeongnam & 0.9088 & 0.1643 & 0.7445 & 0.1381 & 0.5934 & 1.0721 \\
17 & Jeju & 0.6667 & 0.1030 & 0.5637 & 0.0976 & 0.4671 & 0.7936 \\
\hline & Average & 0.7044 & 0.1787 & 0.5257 & 0.1449 & 0.3563 & 0.8929 \\
\hline Standard Deviation & 0.2017 & 0.1756 & 0.1362 & 0.1417 & 0.2398 & 0.3828 \\
\hline & Max. & 1.0000 & 0.5548 & 0.8058 & 0.4572 & 0.7174 & 1.6427 \\
\hline
\end{tabular}

\subsection{Influencing Factors' Analysis by Target Using a Two-Stage Approach}

\subsubsection{Target 11.2: Public Transport}

The results of analyzing the factors influencing target 11.2 are shown in Table 23. Statistically significant factors positively affecting the implementation level (+) of target 11.2 were found to be urban population (POP_URBAN), gross regional domestic product (GRDP), financial independence (FIR), urbanization area (SQUARE_URBAN), and busonly lanes (BUSROAD_LENGTH). The factors negatively affecting the implementation level (-) were identified as population (POP), administrative area (SQUARE), vehicle registration (REG_AUTOMOBILE), and road extension (ROAD_LENGTH).

Table 24. The results analysis of influencing factors for the implementation level of target 11.2.

\begin{tabular}{ccccc}
\hline Coefficients & \multicolumn{3}{c}{} \\
\hline & Estimate & Std. error & z value & Sig. \\
\hline POP & -0.4849 & 0.5412 & -1.2417 & $0.0027^{* *}$ \\
POP_DENSITY & -0.0145 & 0.0248 & -0.1841 & 0.4619 \\
POP_URBAN & 0.4521 & 0.2154 & 1.3112 & $0.0494^{*}$ \\
GRDP & 0.0415 & 0.1484 & 0.3214 & $0.0147^{*}$ \\
FIR & 0.0193 & 0.0784 & 0.2467 & $0.0314^{*}$ \\
SQUARE & -0.0005 & 0.0229 & -0.0203 & $0.0068^{* *}$ \\
SQUARE_URBAN & 0.0767 & 0.0821 & 0.9346 & $0.0332^{*}$ \\
REG_AUTOMOBILE & -0.0532 & 0.0354 & -1.5010 & $0.0419^{*}$ \\
ROAD_LENGTH & -0.0284 & 0.0204 & -1.3933 & $0.0217^{*}$ \\
BUSROAD_LENGTH & 0.0220 & 0.0119 & 1.8427 & $0.0454^{*}$ \\
\hline
\end{tabular}

Significance (Sig.) codes: ${ }^{* *}, 0 ;{ }^{* *}, 0.001 ;{ }^{*}, 0.01$.

Next, the factors influencing each quintile group are shown in Table 24. The population was significant only at the transition level, $\tau$, of $0.6-0.9$, but Table 24 shows that the higher the quartile, the less the population had an influence. The urban population was 
analyzed to be significant only at a $\tau$ of $0.2,0.6,0.7$, and 0.9 , and the higher the quartile, the more positive the effect of the urban population. GRDP was found to have a statistically significant positive $(+)$ effect only at $\tau=0.3$, with a low transition level, or no significant effect in other quantiles. The degree of financial independence was found to be a statistically significant influencing factor only at $\tau$ of $0.2,0.7$, and 0.8 . The urbanization area was found to have a significant positive $(+)$ effect only at $\tau=0.2,0.4,0.5$, and 0.9 . The number of automobile registrations was identified as a statistically significant influencing factor only at the implementation level, $\tau$, of $0.3,0.7$, and 0.9 . In the upper quartile, the negative influencing factors were similar to the result of the influence factor analysis. At $\tau$ of 0.3 , it was as a positive $(+)$ influencing factor, which is a contradictory result compared with the influencing factor analysis result. Road extension was found to be a statistically significant influencing factor only at $\tau=0.4,0.6$, and 0.8 .

Table 25. Target 11.2, comparison of influencing factors by quintile according to implementation level.

\begin{tabular}{cccccccccc}
\hline Coefficients & \multicolumn{1}{c}{$\boldsymbol{\tau} \mathbf{= 0 . 1}$} & $\boldsymbol{\tau}=\mathbf{0 . 2}$ & $\boldsymbol{\tau}=\mathbf{0 . 3}$ & $\boldsymbol{\tau}=\mathbf{0 . 4}$ & $\boldsymbol{\tau}=\mathbf{0 . 5}$ & $\boldsymbol{\tau}=\mathbf{0 . 6}$ & $\boldsymbol{\tau}=\mathbf{0 . 7}$ & $\boldsymbol{\tau}=\mathbf{0 . 8}$ & $\boldsymbol{\tau}=\mathbf{0 . 9}$ \\
\hline POP & -2.6955 & -0.3704 & -0.3971 & -0.6047 & -0.5428 & $-0.3052^{*}$ & $-0.0327^{*}$ & $-0.0450^{*}$ & $-0.0168^{*}$ \\
POP_DENSITY & -0.0108 & -0.0083 & -0.0086 & 0.0009 & 0.0022 & 0.0022 & 0.0004 & 0.0021 & 0.0004 \\
POP_URBAN & 2.3684 & $0.3045^{*}$ & 0.3269 & 0.5168 & 0.4591 & $0.2608^{* *}$ & $0.0250^{*}$ & 0.0436 & $0.0217^{*}$ \\
GRDP & 0.0731 & 0.0343 & $0.0372^{*}$ & 0.0094 & 0.0063 & -0.0073 & -0.0066 & -0.0222 & -0.0182 \\
FIR & -0.0238 & $-0.0078^{*}$ & -0.0124 & 0.0110 & 0.0093 & 0.0260 & $0.0389^{* *}$ & $0.0443^{*}$ & 0.0334 \\
SQUARE & 0.0814 & -0.0337 & -0.0335 & 0.0199 & 0.0168 & 0.0139 & 0.0106 & 0.0108 & 0.0069 \\
SQUARE_URBAN & 0.1680 & $0.0476^{*}$ & 0.0486 & $0.0632^{*}$ & $0.0670^{*}$ & 0.0412 & 0.0046 & 0.0130 & $0.0019^{*}$ \\
\hline REG_AUTO MOBILE & 0.0870 & 0.0360 & $0.0354^{* *}$ & 0.0087 & 0.0003 & 0.0009 & $-0.0016^{*}$ & -0.0014 & $-0.0029^{*}$ \\
ROAD_LENGTH & -0.1659 & -0.0700 & -0.0689 & $-0.0189^{*}$ & -0.0030 & $-0.0066^{*}$ & -0.0058 & $-0.0074^{*}$ & -0.0060 \\
BUSROAD_LENGTH & 0.0005 & 0.0001 & 0.0001 & -0.0005 & -0.0006 & -0.0012 & -0.0021 & -0.0024 & -0.0003 \\
\hline
\end{tabular}

Significance codes: ${ }^{* *}, 0 ;{ }^{* *}, 0.001 ;{ }^{*}, 0.01$.

4.4.2. Target 11.5: Disaster Safety

The results of analyzing the factors influencing target 11.5 are shown in Table 25 . The results of the analysis show that the statistically significant positive $(+)$ factors influencing the target 11.5 implementation level were population density (POP_DENSITY) and GRDP. The negative (-) influencing factors were urban population (POP_URBAN), administrative area (SQUARE), urbanization area (SQUARE_URBAN), and number of automobile registrations (REG_AUTOMOBILE).

Table 26. Analysis results of factors influencing the implementation level of target 11.5.

\begin{tabular}{ccccc}
\hline Coefficients & \multicolumn{3}{c}{} \\
\hline & Estimate & Std. error & z value & Sig. \\
\hline POP & 1.3322 & 0.8535 & 1.5608 & 0.1186 \\
POP_DENSITY & 0.0023 & 0.0183 & 0.1276 & $0.0404^{*}$ \\
POP_URBAN & -1.3347 & 0.6806 & -1.9610 & $0.0499^{*}$ \\
GRDP & 0.2195 & 0.1113 & 1.9726 & $0.0485^{*}$ \\
FIR & -0.1338 & 0.1290 & -1.0366 & 0.2999 \\
SQUARE & -0.0397 & 0.0377 & -1.0546 & $0.0087^{* *}$ \\
SQUARE_URBAN & -0.1268 & 0.1351 & -0.9389 & $0.0347^{*}$ \\
ESTABLISHMENT & 0.0445 & 0.0974 & 0.4562 & 0.6482 \\
REG_AUTOMOBILE & -0.0295 & 0.1078 & -0.2733 & $0.0410^{*}$ \\
\hline
\end{tabular}

Significance codes: ${ }^{* * *}, 0 ;{ }^{* *}, 0.001 ;{ }^{*}, 0.01$. 
The factors influencing each quintile group are shown in Table 26. The population number was not a significant influencing factor, and only $\tau=0.3$ and 0.4 were found to be significant influencing factors. Population density was found to be a statistically significant positive influencing factor. However, in the quantile regression analysis, we found it to be a negative influencing factor in all quantiles except $\tau=0.7$. The urban population was identified as a significant negative influencing factor only at $\tau=0.2$ and 0.4 . GRDP was found to be a significant positive influencing factor only at $\tau=0.1$ and $0.5-0.8$, and it had a positive effect in the higher quartiles, except $\tau=0.9$. The administrative area was only a significant influencing factor for $\tau 0.5,0.6,0.8$, and 0.9 , and it was found to be a negative influencing factor similar to the influencing factor analysis result. Urbanization area was a significant influencing factor only at $\tau=0.3$ and 0.6 , and a negative influencing factor similar to the influencing factor analysis result. The number of automobile registrations was a statistically significant negative influencing factor at $\tau=0.3,0.5,0.6$, and 0.9 .

Table 27. Comparison of influencing factors by quintile according to the implementation level of target 11.5.

\begin{tabular}{ccccccccccc}
\hline Coefficients & \multicolumn{1}{c}{$\boldsymbol{\tau}=\mathbf{0 . 1}$} & $\boldsymbol{\tau}=\mathbf{0 . 2}$ & $\boldsymbol{\tau}=\mathbf{0 . 3}$ & $\boldsymbol{\tau}=\mathbf{0 . 4}$ & $\boldsymbol{\tau}=\mathbf{0 . 5}$ & $\boldsymbol{\tau}=\mathbf{0 . 6}$ & $\boldsymbol{\tau}=\mathbf{0 . 7}$ & $\boldsymbol{\tau}=\mathbf{0 . 8}$ & $\boldsymbol{\tau}=\mathbf{0 . 9}$ \\
\hline POP & 2.1161 & 2.4541 & $2.4123^{*}$ & $1.3265^{*}$ & 0.4371 & 0.2052 & -0.1992 & 0.0763 & $2 \mathrm{E}+00$ \\
POP_DENSITY & -0.0074 & $-0.0199^{*}$ & -0.0324 & -0.0152 & -0.0104 & -0.0064 & $0.0010^{*}$ & -0.0159 & $-9 \mathrm{E}-05^{* *}$ \\
POP_URBAN & -1.8964 & $-2.1408^{* *}$ & -2.1385 & $-1.3266^{*}$ & -0.5972 & -0.4177 & -0.0512 & -0.2695 & $-2 \mathrm{E}+00$ \\
GRDP & $0.0871^{*}$ & 0.0870 & 0.1760 & 0.2611 & $0.3273^{*}$ & $0.3392^{*}$ & $0.3114^{*}$ & $0.3568^{*}$ & $2 \mathrm{E}-01$ \\
FIR & 0.2579 & 0.2786 & 0.1800 & -0.0760 & -0.1877 & -0.2299 & -0.4001 & -0.5064 & $-2 \mathrm{E}-01$ \\
SQUARE & 0.0086 & 0.0248 & 0.0099 & -0.0594 & $-0.0095^{*}$ & $-0.0167^{*}$ & -0.0679 & $-0.1050^{*}-8 \mathrm{E}-02^{* * *}$ \\
SQUARE_URBAN & -0.2872 & -0.4229 & $-0.4683^{*}$ & -0.1797 & -0.1078 & $-0.0527^{* *}$ & 0.0377 & -0.0722 & $-2 \mathrm{E}-01$ \\
\hline ESTABLISH-MENT & -0.0755 & -0.0762 & 0.1103 & 0.0856 & 0.0812 & 0.0802 & 0.0648 & 0.0472 & 0.0078 \\
REG_AUTOMOBILE & 0.1146 & 0.1152 & - & $0.0720^{* * *}$ & -0.0715 & $-0.0714^{* *}$ & $-0.0714^{*}$ & -0.0711 & $-0.0707^{*}$ & $-0.0699^{* *}$ \\
\hline
\end{tabular}

Significance codes: ${ }^{* * *}, 0 ;{ }^{* *}, 0.001 ;{ }^{*}, 0.01$.

\subsubsection{Target 11.6: Environment (Air Quality)}

The analysis results of the influencing factors of the air quality sector of target 11.6 are shown in Table 28. The statistically significant positive influencing factors of the target 11.6 (air quality) implementation level were GRDP, financial independence (FIR), and renewable energy generation (RENEWABLE_ENERGY). The negative influencing factors were the number of population (POP), population density (POP_DENSITY), urbanization area (SQUARE_URBAN), and number of automobile registrations (REG_AUTOMOBILE).

Table 28. Analysis results of factors influencing the implementation level of target 11.6 (air quality).

\begin{tabular}{ccccc}
\hline Coefficients & & & \\
\hline & Estimate & Std. error & z value & Sig. \\
\hline POP & -0.2448 & 0.8751 & -0.2797 & $0.0077^{* *}$ \\
POP_DENSITY & -0.0456 & 0.0187 & -2.4336 & $0.0150^{*}$ \\
POP_URBAN & 0.0972 & 0.6979 & 0.1393 & 0.2470 \\
GRDP & 0.2820 & 0.1141 & 2.4710 & $0.0135^{*}$ \\
FIR & 0.0200 & 0.1323 & 0.1511 & $0.0087^{* *}$ \\
SQUARE & 0.0671 & 0.0386 & 1.7374 & 0.1247 \\
SQUARE_URBAN & -0.1685 & 0.1385 & -1.2163 & $0.0239^{*}$ \\
REG_AUTOMOBILE & -0.4821 & 0.0798 & 1.0071 & $0.0014^{* *}$ \\
SQUARE_GREEN_BUFFER & -0.0119 & 0.0442 & -0.2682 & 0.7885 \\
MANUFACTURING & 0.0136 & 0.0429 & 0.3161 & 0.7519
\end{tabular}




\begin{tabular}{ccccc} 
RENEWABLE_ENERGY & 0.0596 & 0.0297 & 2.0053 & $0.0449^{*}$ \\
\hline Significance codes: & $* * *, 0 ;{ }^{* *}, 0.001 ;{ }^{*}, 0.01$.
\end{tabular}

The factors influencing each quintile group are shown in Table 29. The population amount was a statistically significant influencing factor only at $\tau=0.1,0.2,0.4$, and 0.8 . It was a negative influencing factor even in the lower quartile. Population density was identified as a significant negative influencing factor only at $\tau=0.2,0.4$, and 0.5 . The urban population was not significant in the influencing factor analysis results, but it was significant only at $\tau=0.7$ and 0.8 . GRDP was found to be a significant influencing factor only at $\tau=0.4$, as was urbanization area only at $\tau=0.3$. The number of automobile registrations was identified as a statistically significant influencing factor only at $\tau=0.4-0.7$ and 0.9 . The amount of renewable energy generated was a positive influencing factor that was significant only at $\tau=0.5,0.6,0.8$, and 0.9 , and was a statistically significant influencing factor in the upper quantile, similar to the results of the influencing factor analysis.

Table 29. Comparison of influencing factors by quintile according to the implementation level of target 11.6 (air quality).

\begin{tabular}{|c|c|c|c|c|c|c|c|c|c|}
\hline \multicolumn{10}{|l|}{ Coefficients } \\
\hline & $\tau=0.1$ & $\tau=0.2$ & $\tau=0.3$ & $\tau=0.4$ & $\tau=0.5$ & $\tau=0.6$ & $\tau=0.7$ & $\tau=0.8$ & $\tau=0.9$ \\
\hline POP & $-2.9772^{*}$ & $-2.5551^{* *}$ & -2.4362 & $1.7636^{*}$ & 0.5850 & -0.2399 & -0.3662 & $0.0031^{*}$ & 0.0031 \\
\hline POP_DENSITY & -0.0747 & $-0.0578^{*}$ & -0.0659 & $-0.0474^{*}$ & $-0.0507^{* *}$ & -0.0374 & -0.0058 & 0.0015 & 0.0015 \\
\hline POP_URBAN & 2.3111 & 1.9497 & 1.8142 & -1.4241 & -0.5719 & 0.0473 & $0.3102^{*}$ & $0.0024^{* *}$ & 0.0024 \\
\hline GRDP & 0.6503 & 0.5647 & 0.6276 & $0.0382^{*}$ & 0.2604 & 0.3241 & 0.0536 & -0.0046 & -0.0046 \\
\hline FIR & -0.2537 & -0.1677 & -0.2410 & 0.4873 & 0.0022 & -0.1239 & -0.0641 & 0.0240 & 0.0240 \\
\hline SQUARE & 0.1034 & 0.1079 & 0.0869 & 0.1463 & 0.0374 & 0.0227 & 0.0129 & 0.0208 & 0.0208 \\
\hline SQUARE_URBAN & -0.0379 & 0.0047 & $-0.0273^{* *}$ & -0.5338 & -0.3236 & -0.1283 & -0.0129 & -0.0160 & -0.0160 \\
\hline REG_AUTOMOBILE & 0.1146 & 0.1152 & -0.0720 & $-0.0715^{* *}$ & $-0.0714^{*}$ & $-0.0714^{*}$ & $-0.0711^{* *}$ & -0.0707 & $-0.0699^{* * *}$ \\
\hline SQUARE_GREEN_BUFFER & 0.2866 & -0.0457 & -0.0493 & -0.0236 & -0.0216 & -0.0056 & -0.0037 & -0.0025 & -0.0026 \\
\hline MANUFAC-TURING & -0.2780 & 0.0707 & 0.0694 & 0.0299 & 0.0251 & 0.0060 & 0.0034 & 0.0017 & 0.0017 \\
\hline RENEWABLE_ENERGY & -0.0039 & 0.0779 & 0.0939 & 0.0293 & $0.0310^{* * *}$ & $0.0055^{*}$ & 0.0032 & $0.0018^{* *}$ & $0.0024^{* *}$ \\
\hline
\end{tabular}

\subsubsection{Target 11.6: Environment (Waste Management)}

The results of analyzing the factors influencing target 11.6 (waste management) are shown in Table 30. As a result of the analysis, the statistically significant positive factors influencing the target 11.6 (waste management) implementation level were GRDP, finance independence (FIR), and population density of waste management zones (SQUARE_DENSTIY_WM). The negative influencing factors were the administrative area (SQUARE), urbanization area (SQUARE_URBAN), and waste management area (SQUARE_WM).

Table 30. Analysis results of factors influencing the implementation level of target 11.6 (waste management).

\begin{tabular}{ccccc}
\hline Coefficients & & & & \\
\hline Estimate & Std. error & z value & Sig. \\
\hline POP & 0.1784 & 1.4051 & 0.1270 & 0.8989 \\
POP_DENSITY & -0.0201 & 0.0301 & -0.6687 & 0.5037 \\
POP_URBAN & -0.3009 & 1.1205 & -0.2685 & 0.7883 \\
GRDP & 0.1472 & 0.1832 & 0.8034 & $0.0397^{*}$ \\
FIR & 0.2053 & 0.2124 & 0.9662 & $0.0333^{*}$ \\
SQUARE & -0.0183 & 0.0620 & -0.2955 & $0.0076^{* *}$ \\
SQUARE_URBAN & -0.0065 & 0.2224 & -0.0293 & $0.0497^{*}$ \\
SQUARE_WM & -0.0215 & 0.0320 & -0.6726 & $0.0201^{*}$
\end{tabular}




\begin{tabular}{crrrr} 
SQUARE_DENSITY_WM & 0.0039 & 0.0188 & 0.2086 & $0.0083^{* * *}$ \\
\hline Significance codes: ${ }^{* * *}, 0 ;{ }^{* *}, 0.001 ;{ }^{*}, 0.01$.
\end{tabular}

The influencing factors of each quantile group are shown in Table 31. The degree of financial independence was found to be a statistically significant influencing factor only at $\tau=0.5$ and $0.7-0.9$, but it was a positive influencing factor in the upper quantile in the same way as in the influencing factor analysis result. The administrative area was a significant negative influencing factor only at $\tau=0.4$ and 0.5 , and urbanization area was a significant influencing factor only at $\tau=0.7$. Waste management area was statistically significant only at $\tau=0.2-0.4,0.7$, and 0.8 , generating the same results as in the influencing factors analysis. The population density of waste management area was identified as a significant influencing factor only at $\tau=0.1,0.3$, and $0.5-0.9$, and appeared to be a factor that influences waste management in almost all quantiles, except in the upper quantile $(\tau=$ $0.9)$, where it was found to be a negative factor.

Table 31. Comparison of influencing factors by quintile according to the implementation level of target 11.6 (waste management).

\begin{tabular}{|c|c|c|c|c|c|c|c|c|c|}
\hline \multicolumn{10}{|l|}{ Coefficients } \\
\hline & $\tau=0.1$ & $\tau=0.2$ & $\tau=0.3$ & $\tau=0.4$ & $\tau=0.5$ & $\tau=0.6$ & $\tau=0.7$ & $\tau=0.8$ & $\tau=0.9$ \\
\hline POP & 2.3823 & 2.3823 & 1.2983 & 1.3517 & 1.5040 & 1.2130 & 0.3387 & 0.3927 & 0.3927 \\
\hline POP_DENSITY & -0.0064 & -0.0064 & 0.0140 & 0.0132 & 0.0109 & -0.0014 & 0.0069 & 0.0060 & 0.0060 \\
\hline POP_URBAN & -2.2094 & -2.2094 & -1.1697 & -1.1949 & -1.2669 & -0.9057 & -0.2197 & -0.2571 & -0.2571 \\
\hline GRDP & 0.0597 & 0.0597 & -0.0669 & -0.0843 & -0.1339 & -0.1370 & -0.1060 & -0.1112 & -0.1112 \\
\hline FIR & 0.7568 & 0.7568 & 0.1970 & 0.1776 & $0.1222^{*}$ & 0.2818 & $0.1739 *$ & $0.1790^{* *}$ & $0.1790^{*}$ \\
\hline SQUARE & 0.0950 & 0.0950 & -0.0836 & $-0.0936^{*}$ & $-0.1222^{*}$ & 0.0895 & 0.0506 & 0.0534 & 0.0534 \\
\hline SQUARE_URBAN & -0.2142 & -0.2142 & 0.0218 & 0.0073 & -0.0340 & -0.2958 & $-0.0983^{*}$ & -0.1154 & -0.1154 \\
\hline SQUARE_WM & 0.0477 & $-0.0771^{*}$ & $-0.0363^{*}$ & $-0.0252^{* *}$ & -0.0317 & 0.0020 & $0.0015^{*}$ & $0.0073^{*}$ & -0.0067 \\
\hline SQUARE_DENSITY_WM & $0.0375^{*}$ & 0.0118 & $0.0094^{* *}$ & 0.0036 & $0.0007^{*}$ & $0.0007^{*}$ & $0.0006^{*}$ & $0.0005^{* *}$ & $-0.0054^{*}$ \\
\hline
\end{tabular}

Significance codes: ${ }^{* * *}, 0 ;{ }^{* *}, 0.001 ;{ }^{*}, 0.01$.

\subsubsection{Target 11.7: Public Space}

The results of analyzing the factors influencing target 11.7 are shown in Table 32 . The statistically significant positive factors affecting the target 11.7 implementation level were GRDP, finance independence (FIR), administrative area (SQUARE), and green area (SQUARE_GREEN). The negative influencing factor was the population (POP).

Table 32. Analysis results of factors influencing the implementation level of target 11.7.

\begin{tabular}{ccccc}
\hline Coefficients & & & & \\
\hline & Estimate & Std. error & z value & Sig. \\
\hline POP & -1.0924 & 1.2729 & -0.8582 & $0.0039^{* *}$ \\
POP_DENSITY & 0.0191 & 0.0273 & 0.6999 & 0.4840 \\
POP_URBAN & 0.7382 & 1.0151 & 0.7272 & 0.4671 \\
GRDP & 0.0835 & 0.1660 & 0.5032 & $0.0061^{* *}$ \\
FIR & 0.2217 & 0.1925 & 1.1518 & $0.0249^{*}$ \\
SQUARE & 0.1264 & 0.0562 & 2.2494 & $0.0245^{*}$ \\
SQUARE_URBAN & 0.2768 & 0.2015 & 1.3742 & 0.1694 \\
SQUARE_GREEN & 0.0142 & 0.0273 & 0.5204 & $0.0062^{* *}$ \\
\hline
\end{tabular}

Significance codes: ${ }^{* *}, 0 ;{ }^{* *}, 0.001 ;{ }^{*}, 0.01$.

Next, the influencing factors of each quantile group are shown in Table 33. GRDP was identified as a statistically significant influencing factor only at $\tau=0.5$, and finance independence was analyzed as a significant positive factor at $\tau=0.3,0.6,0.7$, and 0.9 . The administrative area was found to be a significant positive $(+)$ influencing factor at $\tau=0.1$, 
0.6 , and 0.8. The green area (SQUARE_GREEN) was statistically significant at $\tau=0.2,0.4$, and $0.7-0.9$, which is the same analysis result as in the influencing factor analysis.

Table 33. Comparison by quintile of factors influencing the implementation level of target 11.7.

\begin{tabular}{ccccccccccc}
\hline Coefficients & \multicolumn{1}{c}{10.1} & $\boldsymbol{\tau}=\mathbf{0 . 2}$ & $\boldsymbol{\tau}=\mathbf{0 . 3}$ & $\boldsymbol{\tau}=\mathbf{0 . 4}$ & $\boldsymbol{\tau}=\mathbf{0 . 5}$ & $\boldsymbol{\tau}=\mathbf{0 . 6}$ & $\boldsymbol{\tau}=\mathbf{0 . 7}$ & $\boldsymbol{\tau}=\mathbf{0 . 8}$ & $\boldsymbol{\tau}=\mathbf{0 . 9}$ \\
\hline POP & $\mathbf{\tau}=\mathbf{0 . 1 3 3}$ & 2.8487 & -1.7391 & -3.2291 & -2.9159 & -0.3385 & -0.5945 & -0.3294 & -0.3294 \\
POP_DENSITY & 0.0324 & 0.0139 & -0.0148 & $-0.0148^{*}$ & -0.0158 & 0.0237 & 0.0644 & 0.0651 & 0.0651 \\
POP_URBAN & -3.8553 & -2.1763 & 1.4063 & 2.5243 & 2.2709 & -0.0528 & 0.3201 & 0.2265 & 0.2265 \\
GRDP & -0.5821 & -0.3547 & 0.1529 & 0.3740 & $0.3517^{* *}$ & 0.2052 & -0.0978 & -0.2326 & -0.2326 \\
FIR & 1.0240. & 0.7557 & $0.3807^{*}$ & -0.0982 & -0.0686 & $0.1527^{* * *}$ & $0.2630^{*}$ & 0.1688 & $0.1688^{* *}$ \\
SQUARE & $0.2438^{*}$ & 0.2490 & 0.2273 & 0.1294 & 0.1279 & $0.1019^{* *}$ & 0.1084 & $0.0535^{*}$ & 0.0535 \\
SQUARE_URBAN & -0.6698 & -0.5215 & 0.0300 & 0.2850 & 0.2420 & 0.2419 & 0.4119 & 0.3527 & 0.3527 \\
\hline SQUARE_GREEN & 0.0228 & $0.0154^{*}$ & 0.0149 & $0.0024^{* *}$ & 0.0000 & -0.0037 & $0.0875^{*}$ & $0.0793^{* * *}$ & $0.0451^{* *}$ \\
\hline
\end{tabular}

Significance codes: ${ }^{* * *}, 0 ;{ }^{* *}, 0.001 ;{ }^{*}, 0.01$

\section{Conclusions}

\subsection{Summary of Research Results and Implications}

\subsubsection{Level of Korean Urban SDGs Based on the Concept of Relative Efficiency}

For target 11.2, as a result of the implementation level evaluation, based on the scale that provided an important basis for determining the loss of efficiency of local governments, the governments with an efficiency of 1 were divided into 11 regions, including Seoul, Daegu, Incheon, Gwangju, Daejeon, Sejong, Gyeonggi, Chungbuk, Jeonnam, Gyeongnam, and Jeju. In addition, the level of implementation of target 11.2 was found to be excellent overall. The evaluation results revealed that most of the causes of inefficiency of local governments showing low implementation levels were technical factors.

For target 11.5, through the implementation level evaluation, local governments with a scale efficiency of 1 were found to be Ulsan, Sejong, Gyeongnam, and Jeju. All local governments with a low implementation level were in a state of diminishing returns to scale. It is necessary to improve the overall disaster safety policy and seek alternatives to reduce the risk.

Target 11.6 is divided into the air quality sector and the waste management sector on the urban environment agenda, which were analyzed separately in this study.

As a result of evaluating the implementation level of target 11.6 (air quality), local governments with a scale efficiency of 1 were found to be Sejong, Jeonnam, and Jeju. All other local governments were found to be in a state of decreasing return to scale; furthermore, the implementation level of the air quality target (11.6) by Korean local governments was generally low.

By evaluating the implementation level of target 11.6 (waste management), we found that the areas with a scale efficiency of 1 were Gwangju, Ulsan, Sejong, and Chungbuk. Additionally, most local governments were in a state of decreasing return to scale, with considerable room for improvement. The cause of this inefficiency was found to be technical factors.

By evaluating the implementation level of target 11.7, we found that the local governments with a scale efficiency of 1 that showed relatively excellent implementation levels were Seoul, Sejong, and Gyeonggi. In addition, most of the local governments were in a state of increasing return to scale; for most of them, the cause of inefficiency was attributed to technical factors.

Next, the results of DEA-window analysis are presented within a five-year range (2014-2018). 
We found that the transition level of the implementation of target 11.2 was being consistently maintained at a high degree according to the result of the cross-sectional analysis using the standard DEA model. In terms of the transition level due to the change in the scale efficiency score, most local governments showed a transition level of 0.9909 in 2014, 0.9853 in 2015, 0.9897 in 2016, 0.9770 in 2017, and 0.9890 in 2018.

From the analysis, we found that the transition level of the implementation of target 11.5 was maintained at a low level, in agreement with the results of the cross-sectional analysis. In the transition level implementation due to the change in the scale efficiency score, the implementation level of all local governments except for Sejong was high and showed a low level of distribution.

Considering the transition of the implementation level of target 11.6 (air quality), we found that it was generally at a low level for the local governments, except for Sejong, and Seoul and Incheon especially showed very low distribution during the analyzed period.

Regarding the transition of the implementation level of target 11.6 (waste management), no local government indicated had a scale efficiency of 1 during the analyzed period, but Ulsan, Sejong, and Gangwon maintained relatively excellent implementation levels.

Although there is room for improvement, the transition of the implementation level of target 11.7 was found to have remained overall at a good level, except for Jeju.

\subsubsection{Factors Affecting Urban SDGs}

The factors that were influencing the implementation level of Target 11.2 were as follows.

The endogenous influencing factors for each local government were examined by using a common variable as an independent variable among the environmental variables. Regarding target 11.2, the factors positively influencing the implementation level were identified as urban population, GRDP, finance independence, and urbanization area. The population and the administrative area were identified as negative influencing factors. This can be interpreted as a negative influence in terms of providing regular public transport, rather than a quantitative increase in population and administrative area, which are the basic elements of local government.

The impact factors' analysis of the independent variables of the target showed that the factor positively influencing the implementation level of target 11.2 was extension of the bus-only lane, and the factors with a negative influence were the number of automobile registered and road extension. An analysis of these influencing factors separately by transition level suggested that although negative influencing factors were identified, we found that they do not act as negative influencing factors in all conditions, just at certain transition levels. For example, the number of automobiles registered was identified as a factor negatively influencing the level of implementation of target 11.2, but as a result of the quantile, it was identified as a negative factor only in the top level, and as a positive influencing factor in the lower quantile. In other words, the number of registered automobiles had a positive effect for the local governments, through impacts such as traffic jams, congestion costs, accidents, etc., but the analysis showed that for local governments at a relatively low level, cars act as a means of connected transportation. Such an interpretation cannot be generalized to all local governments, but we judged that this hypothesis is not unreasonable in terms of presenting implications of the analysis results. This is because it is easy to understand that in areas where public transportation is not efficiently accessible, individual-owned automobiles can provide a practical means of connected transportation. In areas where the opposite is true, automobiles are used as a means of linking mass transportation to mass transit [1]. This agrees with the research findings reported by Seong et al. [27], who stated that in areas where effective access is difficult, a combination of public transportation and private transportation (cars, bicycles, etc.) can be used, thereby reducing carbon emissions and establishing a user-oriented transportation system. 
Second, the results of the analysis of factors that influence the implementation level of target 11.5 are as follows.

Using common variables as independent variables, the factors positively influencing the target 11.5 implementation level were population density and GRDP, and the negative influencing factors were urban population, administrative area, and urbanization area. This is because the higher the GRDP, which indicates the value of products and services produced in the region at market prices, the better the financial independence of local governments, which enables the independent establishment and deployment of disaster and safety policies consistent with regional characteristics. This suggests that human and property damage resulting from hazards and natural disasters can be reduced, and that precautions can be imparted relatively effectively. Moreover, the finding that population density is a positive influencing factor indicates that it is necessary to maintain the scope of precautionary and post-response management to ensure citizen safety, which is the result of having an appropriate disaster safety policy.

An analysis of the influencing factors by target as independent variables showed that the number of registered automobiles was a statistically significant negative factor affecting the implementation level of target 11.5. With deeper investigation, we found that the increase in the number of registered automobiles was a factor affecting the occurrence of social disasters, from relatively low- to mid- and top-level.

Third, the results of the analysis of the factors influencing the implementation level of target 11.6 (air quality) are as follows.

Using a common variable as an independent variable, for target 11.6, the factors positively influencing the air quality sector performance level were GRDP, fiscal independence, and administrative area, and the negative influencing factors were population, population density, and urbanization. As can be seen from the results of the influencing factors for target 11.5 above, the relationship between GRDP and fiscal independence was found to be positive. As GRDP increases, fiscal independence also improves, and local governments are encouraged to improve air quality. There is also more room for expansion of administrative capacity for investment and policy making. As a result, it can be interpreted that the higher the GRDP and fiscal independence of the region, the easier it is to respond appropriately to environmental issues in the region, including to air quality. The findings of this study may be considered controversial. Bernauer and Koubi [28] suggested through empirical analysis that a negative relationship exists between the size of government expenditure and the quality of the environment, and stated that large-scale environmental expenditure does not always increase the supply of public environmental quality services. Kwon et al. [29] argued that expenditure has no significant effect on the improvement in the actual environmental quality even after the implementation of the air environment budget by the regional government. However, from the perspective that government intervention in environmental issues can be an important factor in determining the quality of the environment as a public service [30,31], the quality of the environment, including air quality management, can be improved. However, the problem is that government intervention has the characteristics of public services. In the private sector, there is a tendency to underinvest: investment in public services is not easily made. Therefore, it is necessary to maintain and improve the quality of the environment at an appropriate level to satisfy the citizens and meet society's expectations, which can be achieved through government finances. The population amount and density, which were found to be statistically significant negative influencing factors, can be interpreted as meaning that citizens can eventually become victims of environmental and air pollution sources. Even if emission standards are strengthened, the increasing pollution generated from citizens (automobile exhaust gas, fine dust, gas originating from energy generation, etc.), as an analysis result reflecting the characteristics of air pollution, is difficult to suppress. Additionally, the market area as a category of complex spaces is a significant source of air pollution due to population movement, housing, activities, economic and production activities, etc. 
The results of the influencing factors' analysis using the variable for each target as an independent variable are as follows: The factor positively influencing the target 11.6 (air quality) implementation level was the amount of renewable energy generated, and the negative influencing factor was the number of registered vehicles. Considering the results of the analysis of these influencing factors by quantile, the amount of renewable energy generated was found to be a significant positive influencing factor at the high level of implementation, and the number of automobile registrations was found to be a negative influencing factor, suggesting that the physical size of the automobile as a source of air quality and air pollution has a negative relationship with air quality.

Fourth, the results of the analysis of the factors influencing the implementation level of target 11.6 (waste management) were as follows.

Using a common variable as an independent variable, positive influencing factors were identified as GRDP and finance independence. If government finance is expanded due to an increase in GRDP, the flexibility of waste management and cleaning budget will be secured. This is meaningful since this financing can shield the citizens from the burden of spending on waste management at an appropriate level.

Based on the influencing factors' analysis using the variable for each target as an independent variable, the positive influencing factor was found to be the population density of the waste management area, and the negative influencing factor was the waste management area. This implies that the central government's administrative support is needed for local governments in provinces that have a relatively wide maintenance area, management of waste sources, and waste management of an appropriate size. Except for some local governments, the area of administrative districts, population density, waste management area, and population density of waste management area were statistically similar, resulting in similar analysis results, but the waste management area and population density are different factors.

Finally, the results of the analysis of the factors influencing the implementation level of target 11.7 were as follows.

The analysis of the factors influencing the common variables as independent variables showed that GRDP, financial independence, and administrative area were the positive influencing factors. This can be interpreted as that the financial conditions of local governments are essential to creating public spaces, as are other factors influencing other detailed objectives. A large administrative area facilitates securing available space to provide public space.

In reference to the influencing factors' analysis with variables by target as independent variables, green areas were shown to be influencing factors positively improving citizens' quality of life; thus, it is crucial to ensure the systematic management of green areas as potentially available and high-quality public spaces.

\subsubsection{Applicability of the Evaluation Framework Based on the Concept of Relative Effi-} ciency

The evaluation framework presented in this study is based on the recognition that the problem with realizing the urban SDGs is similar to the problem of providing public services by local governments.

Considering the argument that efficiency evaluation is needed without distinction, as reviewed in the theoretical discussion, given the public sector's full-fledged contemporary context and the need for discussion of efficiency theory as a means of evaluating the implementation level, achieving the targets of urban SDGs is consequently a local government's responsibility.

Given this recognition, the core of this evaluation framework is to evaluate the relative efficiency of the relationship between the two by viewing public resources such as public officials, budgets, infrastructure, and equipment as inputs, and considering citizen satisfaction, performance, and improvement as a result of the inputs. 
By performing an analysis using the framework designed in this study, the application level of the framework was discussed as follows.

First, the framework based on relative efficiency theory can be used to evaluate the relationship between inputs and outputs, providing intuitive and detailed information about the level of implementation.

Second, if the DEA model introduced in this framework can mitigate the limitations of non-parametricity by other means, it can also provide statistically significant information by identifying factors that have affected the implementation level through appropriate constructions of additional variables. In this study, we further applied a bootstrapping DEA model to estimate $95 \%$ confidence intervals, mitigating the limitations of the nonparametric model while deriving key variables for further analysis. The composition of additional variables to derive influencing factors can be relatively freely varied in terms of unit constraints, depending on the perspective of the researchers or decision makers.

Finally, by tracking the time-series change in the implementation level, it is possible to forecast the future implementation level. Although future monetary values and population estimates should be considered, the prospect of improving the level of implementation will be possible by adjusting the scale of inputs and outputs that have affected the past and present levels of implementation.

As the implementation level can be objectively evaluated, the presented essential information for improvement provides room to further expand the applicability of the framework. However, it is challenging to consider political factors such as policy directions or pledges of decision makers due to the excessively demanding quantification of the data analysis. Therefore, additional efforts to quantify qualitative factors is a future task to improve this evaluation framework.

\subsection{Limitaions of Research and Future Research Projects}

In this study, we performed a quantitative evaluation of the level of urban SDGs' implementation in order to complement previous studies. We provided a meaningful contribution to the literature by evaluating the implementation level of the targets that comprise the urban SDGs at the local government level, and provided implications for deriving influential factors.

Nevertheless, this study has the following limitations, and we note some future research challenges. First, the input and output variables and environmental variables used in this study may vary depending on which indicators are selected. Second, to assess the implementation level of the most desirable urban SDGs, it would be ideal to cover all variables related to the scope of the analysis. Although some indicators are more representative than those used in this study, empirical analyses were performed using these indicators due to the limitations in terms of realistic metric acquisition and composition. Therefore, future studies need to construct more representative indicators, and interpret the qualitative factors that can affect the realization of urban SDGs through quantitative analysis results. Third, it is necessary to further refine the analysis scope to increase the generalizability of the findings. In this paper, we considered the implementation and monitoring of urban SDGs at the regional level. Although the implementation was evaluated at the metropolitan level and implications were derived, local governments failed to provide implications regarding the implementation level that reflected these differences, despite functional differences in population structure, industry, local heads' policy goals, financial conditions, and public sector structure. Therefore, future studies should attempt to evaluate the implementation level according to the size or characteristics of the region by clustering basic autonomous entities that exhibit similar population structures or functional distributions.

Finally, we aimed to present implications of the evaluation and analysis results of implementation levels by quantitative targets. However, no detailed suggestions were provided regarding enhancing the implementation level, such as directionality or improvement measures. Since this study focused on presenting a framework for evaluating 
the implementation level of urban SDGs in terms of complementing prior research, direct causal relationships could not be identified to derive suggestions or policy implications for enhancing the implementation level. Future research will require efforts to improve the completeness of the method by further analyzing expert surveys or international organization-sponsored surveys.

Author Contributions: Jonghoon Yoo - Data curation, formal analysis, investigation, resources, software, writing-original draft; Minkyoung Choi - Validation, visualization, writing-review and editing; Byungseol Byun - Methodology, project administration, supervision, funding acquisition. All authors have read and agreed to the published version of the manuscript.

Funding: This work was supported by the Inha University Research Grant under Grant INHA-65580.

Conflicts of Interest: The authors declare no conflict of interest.

\section{References}

1. Yoo, J.H. A Framework to Evaluate Implementation Level of the UN Sustainable Development Goals(SDGs) Urban Agenda based on the Efficiency Concept. Doctoral thesis, Inha University, Incheon, 2020.

2. SDSN, The Urban Opportunity: Enabling Transformative and Sustainable Development(Background Paper for the High-Level Panel of Eminent Persons on the Post-2015 Development Agenda), SDSN: New York, USA, 2013.

3. SDSN; University of Baltimore. Baltimore's Sustainable Future: Localizing the UN Sustainable Development Goals, Strategies and Indicators(report Prepared for the USA Sustainable Cities Initiative), 2016.

4. UN HABITAT, Sustainable Cities and Human Settlement in the Post-2015 UN Development Agenda, New York: UN, USA, 2014.

5. UN. Transforming Our World: the 2030 Agenda for Sustainable Development(A/70/1), UN: New York, USA, 2015.

6. Kim, T.W. Social welfare program development and evaluation; Hakjisa: Seoul, Korea, 2004.

7. Kim, K.W. A Study on Measuring Efficiency of Local Government Informatization through DEA. Doctoral thesis, Myungji University, Seoul, 2003.

8. Lovell, C.K. Production Frontiers and Productive Efficiency, Oxford University Press: New York, USA, 1993.

9. Lee, J.D.; Oh, D.H. Theory of Efficiency Analysis; Jiphill Media: Seoul, Korea, 2012.

10. Ko, K.K. Theory of Efficiency Analysis; Moonwoo: Goyang, Korea, 2017.

11. Seong, J.H.; Lee, E.Y.; Jeong, Y.W.; Lim, J.B.; Yoo, J.H.; Jeong, S.T. A study on the linkage plan of LH business according to the promotion of the Sustainable Development Goals (SDGs); Land and Housing Institute: Daejeon, Korea, 2015.

12. Lim, J.B.; Jeong, Y.W.; Seong, J.H. A Study on Korea New Town Development's International Advantages on UN Sustainable Development Goals' City Indicators (SDG-11). Journal of The Korean Regional Development Association 2019, Vol. 31, pp. 39-66.

13. Jeong, Y.K. Social learning in the process of making urban SDGs : the case of Suwon, Korea. Doctoral thesis, University of Seoul, Seoul, 2019.

14. Han, S.M. A study on the development and application of evaluation indicator for sustainable urban development and management. Doctoral thesis, Hanyang University, Seoul, 2019.

15. Simon, D.; Arfvidsson, H.; Anand, G.; Bazaz, A.; Fenna, G.; Foster, K.; Jain, G.; Hansson, S.; Evans, L.M.; Moodley, N.; Nyambuga, C.; Oloko, M.; Ombara, D.C.; Patel, Z.; Perry, B; Primo, N.; Revi, A.; Niekerk, B.V.; Wharton, A.; Wright, C. Developing and Testing the Urban Sustainable Development Goal's Targets and Indicators: a Five-city Study, Environment and Urbanization 2015, Vol. 28, pp. 49-63.

16. Satterthwaite, D. Successful, Safe and Sustainable Cities: towards a New Urban Agenda, Commonwealth Journal of Local Government 2016, Vol. 19.

17. Sietchiping, R.; Jane, R.; Omwamba, J. Implementing the SDGs and the New Urban Agenda, Environment and Urbanization ASIA 2016, Vol. 7, pp. 10-12.

18. Valencia, S.C.; Simon, D.; Croese, S.; Nordqvist,J. ; Oloko, M.; Sharma, T.; Buck, N.T.; Versace, I. Adapting the Sustainable Development Goals and the New Urban Agenda to the City Level : Initial Reflections form a Comparative Research Project, International Journal of Urban Sustainable Development 2019, Vol. 11, pp. 4-23.

19. Ozcan, Y.A. Health Care Benchmarking and Performance Evaluation: An Assessment Using Data Envelopment Analysis(DEA), 2nd ed.; Springer: Berlin, Germany, 2014.

20. Son, H.W. A study on efficiency \& its affecting factors of Korean local governments' public services. Doctoral thesis, Hanyang University, Seoul, 2012.

21. Cooper, W.W.; Seiford, L.M.; Tone, K. Data Envelopment Analysis, 2nd ed.; Springer: Berlin, Germany, 2006.

22. Emrouznejad, A.; Amin, G.R. DEA Models for Ratio Data : Convexity Consideration, Applied Mathematical Modelling 2009, Vol. 33, pp. 486-498. 
23. Sarkis, J. Preparing Your Data for DEA, Productivity Analysis in the Service Sector with Data Envelopment Analysis, 3rd ed.; N. K. Avkiran, 2006.

24. Cooper, W. W.; Seiford, L.M.; Zhu, J. Handbook on Data Envelopment Analysis; Springer: Berlin, Germany, 2011.

25. Kneip, A.; Park, B.U.; Simar, L. A Note on the Convergence of Nonparametric DEA Efficiency Estimates, Econometric Theory 1998, Vol. 14, pp. 783-793.

26. Shin, Y.H. The determinants of local finance efficiency : 2-stage bootstrap-DEA truncated-regression analysis. Doctoral thesis, Dankook University, Seoul, 2008.

27. Seong, J.W.; Lim, J.B.; Lee, E.Y.; Jeong, Y.W.; Choi, D.S.; Kim, T.K.; Song, Y.I.; Yoo, J.H. Study on guidelines for new Korean town; Land and Housing Institute: Daejeon, Korea, 2017.

28. Bernauer, T.; Koubi, V. States as Providers of Public Goods: How Does Government Size Affect Environmental Quality?; The center for Comparative and International Studies: Zurich, Switzerland, 2006. Retrieved form ssrn.com/abstract=900487.

29. Kwon, H.Y.; Jung, C.H.; Kim, Y.P. The Impact of Local Government's Expenditure on Air Quality in Korea. Journal of Korean Society for Atmospheric Environment 2016, Vol. 32, pp. 583-592.

30. Lopez, R.; G.I. Galinato; Islam, A. Fiscal Spending and the Environment: Theory and Empirics, Journal of Environmental Economics and Management 2011, Vol. 62, pp. 180-198. 